Journal of Engineering and Applied Sciences 15 (2): 659-678, 2020

ISSN: 1816-949X

(C) Medwell Journals, 2020

\title{
Review of Steady State Visually Evoked Potential Brain-Computer Interface Applications: Technological Analysis and Classification
}

\author{
${ }^{1,2}$ Sebastián Poveda Zavala, ${ }^{1,2}$ José Luis Murillo López, ${ }^{1,2}$ Kelvin Ortíz Chicaiza and \\ ${ }^{1,2}$ Sang Guun Yoo \\ ${ }^{1}$ Departamento de Informática y Ciencias de la Computación, Escuela Politécnica Nacional, \\ Quito, Ecuador \\ ${ }^{2}$ Smart Lab, Escuela Politécnica Nacional, Quito, Ecuador
}

\begin{abstract}
Brain-computer interface is a technology which creates a new way of communication between a person's brain and the external world. To achieve this objective, the brainwaves of a person must be gathered by using specialized devices and then classified in different categories that are associated with specific commands. In the process of brainwave gathering, brain activities of a person can be influenced by different types of stimuli to get the desired results and one of the most important and popular stimuli used in this field is steady state visually evoked potential. Based on this background, this review seeks to show and analyze a series of articles that have been executed around the world related to brain-computer interface applications using steady state visually evoked potential. This review has been executed with the objective of identifying the advantages and limitations of utilizing steady state visually evoked potentials, its main areas of application and the future challenges. Additionally, this review analyzes the different technologies involved to the implementation of state visually evoked potential systems such as signal classification techniques, electroencephalography devices, channels, verification metrics and experimental environments used in the research projects. In summary, this review intends to guide the scientific community about the different aspects involved in conducting research on the development of brain-computer interface applications using electroencephalography devices and steady state visually evoked potential.
\end{abstract}

Key words: Brain computer interface, steady state visually evoked potentials, BCI, SSVEP, BCI applications, electroencephalography

\section{INTRODUCTION}

Brain-Computer Interface (BCI) is a technology that uses signals gathered from the brain of a person to enable communication with the external world. Although, BCI may seem like a novel concept, it was first introduced by the researcher Jacques J. Vidal in 1973 who presented the term, the vision and some ideas of what this technology could achieve Nam et al. (2018). And with almost 50 years of antiquity, the main milestones of the field were achieved even before; like the birth of the Electroencephalography (EEG) concept Berger (1929), the description of contingent negative variation Walter et al. (1964) or the beginning of neurofeedback Kamiya (1968). Despite such achievements, there were no significant advances until this century when important real-life projects began to appear Shih et al. (2012). Those projects received the attention of the scientific community and followed in new researches that allowed the progress of this field.

In order to implement a functional application, a BCI system must be able to capture the signals of the brain, process them, i.e., extracting specific characteristics and identifying the user's intentions and execute the functionalities selected by the user He et al. (2013). In this aspect, brainwave acquisition is indispensable for the implementation of a BCI system and for such process, a large number of techniques have been developed. Those techniques can be divided into two large categories, i.e., invasive (which uses surgical implants in the brain for signal acquisition) and non-invasive (which does not require a surgical implant for signal acquisition) Graimann et al. (2009). Invasive techniques allow getting data with higher quality, however, they are not widely used because they require surgical operations that can bring medical complications. On the other hand, non-invasive techniques are widely used since there are no health risks and they have a much easier implementation feature. Within the category of non-invasive BCI, various technologies are used to capture brain signals. Among them, the most important technologies include: functional Magnetic Resonance Imaging (fMRI) based on measuring changes in blood flow Rios-Lago (2008), Functional Near-Infrared 
Spectroscopy (fNIRS) (which uses infrared light to measure characteristics of specific cortical regions) Bunce et al. (2006), Magnetoencephalography (MEG) (which is based on measuring magnetic induction in neuronal cells) Hamalainen et al. (1993) and Electroencephalography (EEG) (which yields a record of brain bioelectric activity) Zhang et al. (2017a, b). And among the mentioned technologies, EEG is considered as the most popular and accessible method for most researchers, since, there are more variety of devices that meet their needs in the market i.e., portability, ease of use, number of brainwave channels and price Thakor and Sherman (2013).

According to the International Federation of Clinical Neurophysiology, EEG is defined as "the science relating to the electrical activity of the brain and the technique of recording electroencephalograms” Steriade et al. (1990). In recent years, a large number of EEG based BCI systems have been developed thanks to the release of different low-cost devices that allows recording brain signals at a constant rate i.e., Muse headband, OpenBCI, emotiv EPOC. Additionally, the development of different technologies to analyze and use the brain signals gathered using EEG such as ERD/ERS (event-related desynchronization and event-related synchronization), P300, motor imagery and SSVEP (Steady State Visual Evoked Potentials) Bi et al. (2013), also helped the expansion of BCI systems based on EEG. In this aspect among the aforementioned technologies for analyzing and using brainwaves, one of the most important is SSVEP. SSVEP makes use of brainwaves generated by visual stimulation responses when a subject looks at a light source flickering at a specific frequency. SSVEP's usage has grown considerably, since, it is easy to implement in real life applications, denoting more than anything benefits such as the use of few channels to get accurate results and the short training time needed by the user.

Due to the importance of EEG and SSVEP in BCI systems, this review presents a detailed study of different application researches done using the aforementioned technologies. This review has the purpose to deliver a systematic literature review of the latest BCI applications that uses EEG and SSVEP to help people understand the new trends of applications in this area and the different technologies involved in the implementation of those applications.

\section{MATERIALS AND METHODS}

To fulfill the purpose of this review, we have conducted a systematic review of different researches that focus on BCI systems based on EEG and SSVEP. For this process, we adopted the approach described by Arksey and O’Malley which is commonly used in researches involving health. This method offers a way to examine the extent and nature of the research regardless of the quality of the study Arksey and O’Malley (2005).

Criteria of inclusion and exclusion: Scientific articles reviewed were selected based on the following criteria:

- $\quad$ Articles published since, January, 2012

- The BCI system must use EEG and SSVEP technologies

- $\quad$ Since, the purpose of this review is focused on the implementation of real-world applications, researches that only focus on signal classification and modeling were excluded

Search strategy and results: The search was performed in various scientific databases including IEEE Xplore, ACM Digital Library, ScienceDirect, SemanticScholar, Scopus, Springer and Hindawi. The words BCI, EEG, SSVEP, control and application were searched in titles, keywords and abstracts of articles. Once the search was done, 110 articles were collected. After reviewing their complete content, we proceeded to exclude those articles not focused on BCI applications and those not using SSVEP responses. After such exclusion, the whole set of articles were reduced to 40 which were selected as the target of analysis of this review. Figure 1 shows the details of the article selection process.

Review of EEG-SSVEP application: In the field of neuro-engineering, Steady State Visually Evoked Potentials (SSVEP) is defined as a set of signals that are captured when there is a certain visual stimulation at specific frequencies called Visual Evoked Potentials (VEP). Registered VEPs are activated by sensory stimulation of a subject's visual field and they reflect visual information processing mechanisms in the brain Wang et al. (2006). A BCI system that uses VEP can identify the object in which the user is focusing their attention, through an analysis of the EEG signals recorded in real time. To ensure reliable identification, VEPs derived from different stimulus sequences are registered and usually classified to a frequency domain Vialatte et al. (2010). SSVEPs are widely used with EEG since it delivers excellent signal-to-noise ratio and relative insusceptibility to artifacts. In this sense, the growing interest of the scientific community for BCI systems that are lightweight, easy-to-use inexpensive and non-invasive has allowed EEG-SSVEP to be applied in a variety of solutions in different areas. Based on this background, this review has analyzed the most recent research articles related to EEG-SSVEP implementations intended to be used in real life. The reviewed articles were classified in different categories as shown in Fig. 2.

Health applications: According to the World Health Organization, between 20 and 50 million people around the world suffer from injuries caused by car accidents that 


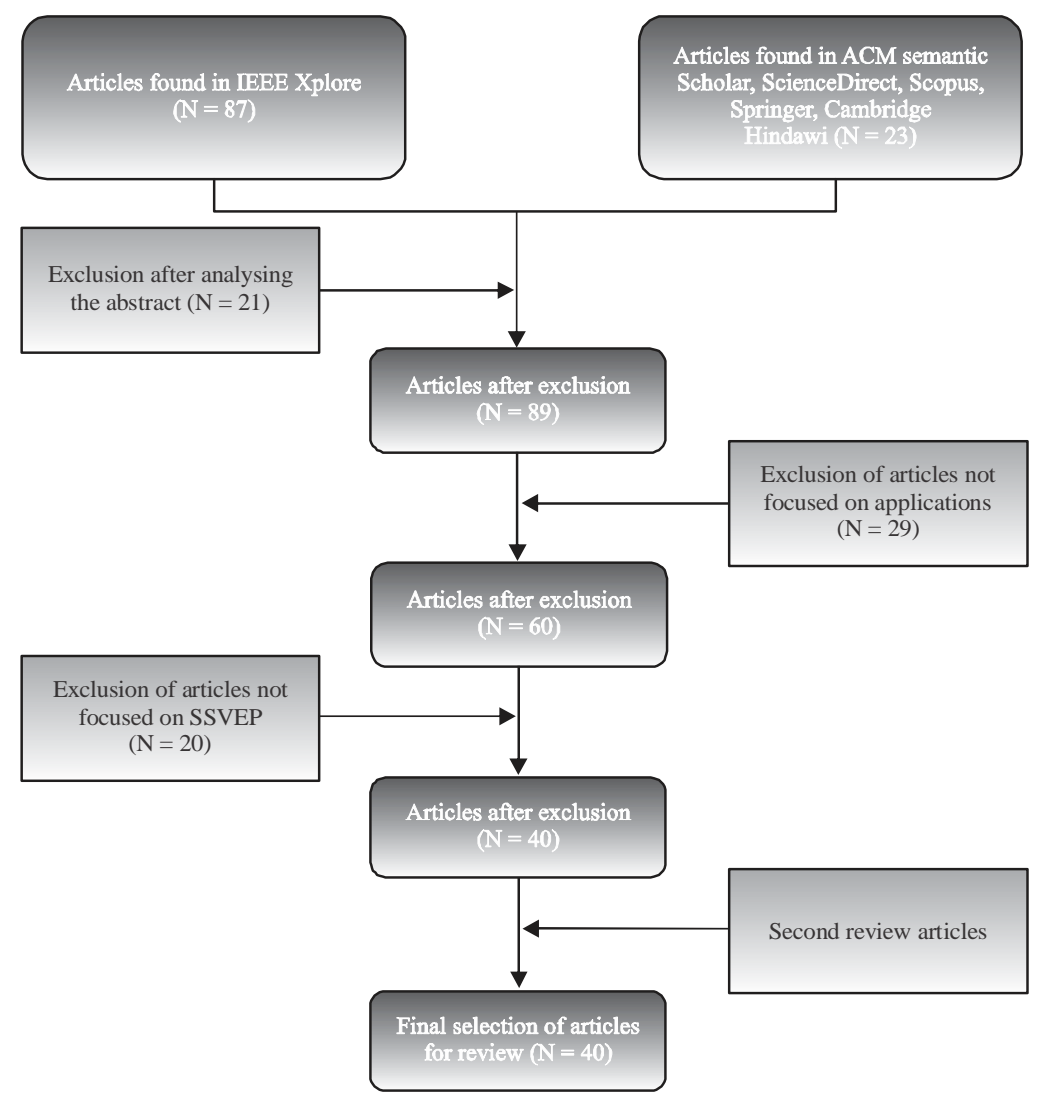

Fig. 1: Diagram of articles selection process

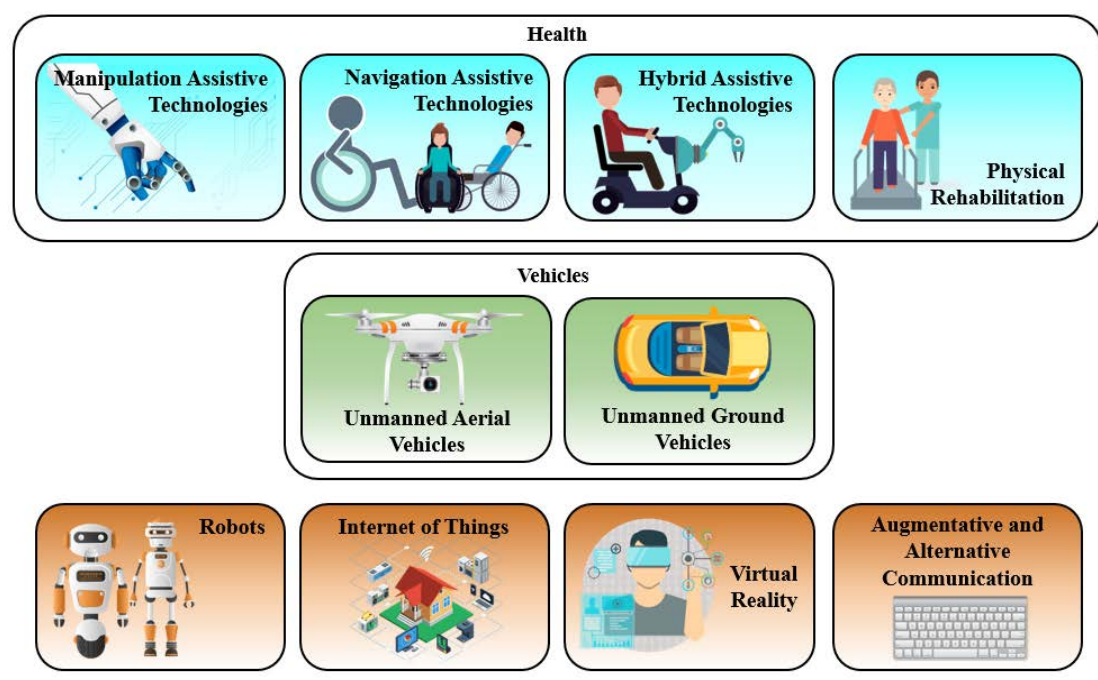

Fig. 2: Categories of BCI applications based on SSVEP

result in temporary or permanent disabilities Road safety (2018). Considering this statistic, health is one of most benefited fields of BCI systems based on SSVEP, since, this technology can improve the quality of life of people who suffer from Motor Neuron Diseases (MND) or other types of movement disabilities. Health applications can be divided into manipulation assistive technologies, navigation assistive technologies, hybrid assistive technologies and physical rehabilitation tools.

Manipulation assistive technologies: Manipulation assistive technologies are focused on providing support 
for people who have difficulties to perform daily tasks. Some examples of this type of technologies are electric hospital bed proposed by Peng et al. (2016), an assistant arm for patient feeding Perera et al. (2016, 2017), the control of a transhumeral prosthesis Ruhunage et al. (2017) and robotic arms Yang et al. (2017); Zhang et al. (2017a, b); Pelayo et al. (2018); Zhang et al. (2012).

Among the reviewed articles, Peng et al. (2016) proposes an electric hospital bed controlled by SSVEP-P300 combination responses. SSVEP is used to turn on/off and control the bed. Different frequencies, 6.0, 6.67, 7.5 and $8.57 \mathrm{~Hz}$ are displayed in the corners of the screen and they are used to select one of 4 commands. Among the 4 commands, only one is used at the moment. The brain signals are filtered using a bandpass of 0.1-20 $\mathrm{Hz}$ and then classified using power ratios obtained by using Minimum Energy Combination (MEC) and Discrete Fourier Transform (DFT) methods. On the other hand, P300 is used to control the main functions of the bed.

Within the robotic arm control implementations we have Perera et al. (2017, 2016); Ruhunage et al. (2017a, b); Yang et al. (2017); Zhang et al. (2017); Pelayo et al. (2018); Zhang et al. (2018), several solutions are presented. According to Perera et al. (2017), the researchers developed a BCI system to control a robotic arm that aids in people's feeding process. The system was created to help people with any type of movement limitations in their upper limbs. The frequencies used for this system were 6, 7 and $8 \mathrm{~Hz}$. The system processes the brain signals by means of spatial and high-pass filters and the frequency domain is extracted and classified using a simple threshold and Fourier transform. Similarly, the research Perera et al. (2017) proposes a system for controlling a robotic food assistance arm. The system uses 6, 7 and $8 \mathrm{~Hz}$ to control an arm with 4 Degrees of Freedom (DOF). The signals are processed with high-pass filter and fourier transform, then, they are classified with an algorithm based on a threshold.

On the other hand, the work presented by Ruhunage et al. (2017) proposes an arm prosthesis composed of an elbow (controlled by EMG signals) and a hand (controlled by EEG-SSVEP signals). This system works with a single frequency of $6 \mathrm{~Hz}$ for hand control. The data is processed as follows: first, the signals are handled by an algorithm developed by the authors; then, a filter based on high-pass differentiation and fourier transform are applied; later, the frequency intervals (thresholds) that will be used for the classification are extracted; and at the end, the command is executed when 5 consecutive positive ratings are obtained.

Another manipulation assistive technology application is the one presented by Zhang et al. (2017a, b). In such research, the authors present a hybrid BCI system that uses SSVEP responses, motor imagery, computer vision and artificial intelligence. All the technologies are applied in order to control a robotic arm to grasp objects. The operation of the system is based on detecting objects in a certain area. Once the object is detected, it is selected through SSVEP responses using a panel that generates different visual stimuli. The robotic arm approaches the selected object using artificial intelligence algorithms and sends the commands to open and close the hand by means of Electrooculography (EOG) signals.

Similarly, Zhang et al. (2017ab) shows a BCI system that uses SSVEP responses in order to control a robotic arm. The system classifies the signals into 4 categories. 4 $\mathrm{Hz}$ to move left, $4.615 \mathrm{~Hz}$ to move right, $5,455 \mathrm{~Hz}$ to move up and $6 \mathrm{~Hz}$ to move down. The operation of the system is based on amplified brain signals generated when the user looks at a screen. These signals pass through a fourth order filter in order to eliminate noises and detect the command and once the desired command is detected, it is sent to the robotic arm to perform the movement.

In the same way, Pelayo et al. (2018) presents a system that allows users to control a robotic arm through EEG signals based on SSVEP responses. The operation of the system is based on controlling 3 servomotors (servo 1: change the orientation, servo 2: change the angle, servo 3 : change the claw's opening) using signals generated by the brain of the user when he/she looks at 3 LED lights of different frequencies (servo 1: $7 \mathrm{~Hz}$, servo 2: $11 \mathrm{~Hz}$, servo 3: $15 \mathrm{~Hz})$.

Finally, Yang et al. (2017) presents a shared control of a robotic arm which combines SSVEP and vision sensor. The operation of the system is based on the visualization of target objects using a camera integrated into the robotic arm. Each object has blinking diamonds which generate the SSVEP stimuli needed to invoke the commands that allow the user to choose the objects. On the other hand, the vision sensor technology allows detecting the positions of the objects.

Navigation assistive technologies: Navigation assistive technologies are created to provide support to people with disabilities in order to help them be more independent with their mobility. One type of solution of this technology is the user controlled wheelchair presented by Li et al. (2013); Turnip et al. (2015a-c); Andronicus et al. (2015); Turnip et al. (2016); Turnip et al. (2017, 2017); Turnip and Mistry et al. (2018). There are several techniques that can be used for delivering user control to wheelchairs but SSVEP is one of the most popular because of its accuracy and usability. Research works analyzed in this review vary in their configurations but they all focus on four frequencies to control the wheelchair. Li et al. (2013), the authors make use of an hybrid system proposed by Peng et al. (2016) to control the wheelchair while Turnip et al. (2016) proposes an 
electric wheelchair control system using 6-9 $\mathrm{Hz}$ frequencies to execute turn left, turn right, go back and go forward commands, respectively; the signals are processed and classified using a sixth order Bandpass Filter (BPF) with cutoff frequencies of 4 and $30 \mathrm{~Hz}$ and an Adaptive Neuro-Fuzzy Inference System (ANFIS). Turnip et al. (2015a-c) also uses an ANFIS classifier but extracts the signals characteristics by using a Nonlinear Adaptive Filter (NAF) and estimates the parameters of the signals by using a self-regressive model; the data used as input of the classifier are also pre-processed by a sixth order bandpass filter with 4 and $30 \mathrm{~Hz}$ cutoff frequencies. The system works with images at $6-9 \mathrm{~Hz}$ frequencies that are displayed in a Graphical User Interface (GUI) combined with the task of imagining the movement of the chair in the desired direction.

On the other hand, the work indicated by Mistry et al. (2018) adds proximity sensors to the wheelchair to provide a way to prevent collisions; if sensors detect an obstacle at a distance of $50 \mathrm{~cm}$ or less, then the movement of the wheelchair to such direction is not performed. The system processes the SSVEP signals generated by the stimuli of 4 frequencies ( $7 \mathrm{~Hz}$ turn left, $9 \mathrm{~Hz}$ go forward, $11 \mathrm{~Hz}$ turn right and $13 \mathrm{~Hz}$ go back) by means of Fourier transforms and SNR classification.

Additionally, systems proposed by Turnip et al. (2017) use frequencies of 7.5, 10, 15 and $20 \mathrm{~Hz}$ with an Adaptive Feedforward Neural Networks (AFNN) classifier to perform the control of the wheelchair. Being more specific, Turnip et al. (2017) uses the aforementioned frequencies to advance, stop, turn right and turn left, respectively and processes the signals using a bandpass filter with a Chebyshev method with cutoff frequencies of 7 and $30 \mathrm{~Hz}$, to then classify them using the AFNN. Meanwhile, Turnip et al. (2017) uses the frequencies to stop, advance, turn right and turn left, respectively and processes the signals using a bandpass filter with cutoff frequencies of $7.5-20 \mathrm{~Hz}$ with an attenuation of $-10 \mathrm{~dB}$, to then pass through a stop-band filter with cutoff frequencies of $5-30 \mathrm{~Hz}$ and with an attenuation of $-40 \mathrm{~dB}$, to finally, classify them using the AFNN.

Although, many of the articles detail the frequencies they use Andronicus et al. (2015) and Turnip et al. (2016) do not. Andronicus et al. (2015) focuses on explaining the construction of a system with the minimum amount of electrodes to make more comfortable to use. This system consists of 3 parts: a pre-processing stage that uses a "centering process" to eliminate data offset, a feature extraction stage based on 4 bandpass filters with "14-order Chebyshev Type 2 IIR" and Power Spectral Density (PSD) estimation using the Welch method and a classification stage based on a "threshold and voting" system for classification into 4 patterns: forward, stop, left, right. Finally, Turnip et al. (2016) details that its operation is based on the processing of signals through, a bandpass filter, noise elimination by Wavelet and Fourier transforms and classification of signals through ANFIS.

Hybrid assistive technologies: In the literature review, we found a solution that combines manipulation assistive and navigation assistive technologies in a single system by implementing the control of a wheelchair with a robotic arm. In such work, Achic et al. (2016) presents a BCI system that uses EMG and EEG waves to control a robotic arm that is connected to an electric wheelchair. This system uses the SSVEP responses based on $14-7 \mathrm{~Hz}$ frequencies for controlling the robotic arm. The SSVEP signals are processed by a fourth order Butterworth low filter with a $50 \mathrm{~Hz}$ cutoff frequency, Fourier transforms and frequency domain classification.

Physical rehabilitation: Systems in this category provide help to people who have difficulty to move, so that, they can restore their lost capabilities and recover the levels of mobility they previously had. Additionally in some cases, these solutions can help them to adapt to the acquired disabilities.

The work presented by Gui et al. (2015) proposes an exoskeleton system that aims to help people in lower extremities rehabilitation process. The selected SSVEP frequencies used by the system are 6.82, 7.5, 8.33 and $12.5 \mathrm{~Hz}$ which give the functions of decelerating, accelerating, normal walking and braking of the exoskeleton, respectively. The system processes the signals with a filter that cuts the frequencies between 0.05-60 Hz and classifies them using Linear Discriminant Analysis (LDA) and Container Strategy (CS) algorithms devised by the authors. In the end, the system makes the decision by using a central pattern generator algorithm which tells the exoskeleton the movements to perform.

On the other hand, Savic and Popovic (2016) shows 3 versions of a system for functional electrical stimulation. While the first version uses SSVEP and ERD signals, the next two versions work only with ERD signals. The frequencies used for SSVEP were between a range of 15 and $24 \mathrm{~Hz}$. The system filters the SSVEP signals with six fourth order Butterworth bandpass filters with a bandwidth of $1 \mathrm{~Hz}$ and the filtered signals are classified using band power thresholds.

Vehicle control: In recent years, the research of BCI have explored new fields of application and one of the most important has been the control of different types of vehicles including the unmanned aerial vehicles proposed by Wang et al. (2018); Khan et al. (2016) and unmanned ground vehicles in Lee et al. (2012); Zhang et al. (2011); Diez et al. (2014); Gonzalez-Mendoza et al. (2015); Farmaki et al. (2016); Stawicki et al. (2016); Wu et al. (2016) and Liu et al. (2018). 
Unmanned aerial vehicles: In the field of Unmanned Aerial Vehicles (UAV), the work presented by Wang et al. (2006) shows a system that controls a quadrotor helicopter using an encephalogram system and a virtual reality device. The objective of the system is to control the pitch, yaw and roll movements of a helicopter through SSVEP responses. The system has two states, the transitional state and the stable state. To determine the state in which the system is, the data of the head position of the virtual reality device (i.e., HTC VIVE) is used during the SSVEP session.

Similarly, Khan et al. (2016) proposes the scheme for a quadcopter through the use of several signals. Four brain signals are decoded using a hybrid Electroencephalogram (EEG) -Near Infrared Spectrum (NIRS) system. The signals obtained by NIRS are used to move the quadcopter forward while the decoded EEG signals are used to increase and decrease the height; meanwhile, SSVEP is used as a security mechanism to avoid collisions by stopping the command in execution. Horizontal eye movements are used to control the rotation of the quadcopter.

Unmanned ground vehicles: In the field of unmanned ground vehicles, article Diez et al. (2014) presents an asynchronous machine-man interface that allows the navigation of a motor vehicle and it is based on a high-frequency SSVEP. In the aforementioned system, SSVEP signals are generated by four stimulation boxes around a monitor that generate frequencies of $37-40 \mathrm{~Hz}$ while the monitor shows a real-time video that the vehicle perceives.

Additionally, the control of Remote Control (RC) cars using brainwaves is explored in different articles. Lee et al. (2012) presents a system that uses SSVEP responses for driving an RC car; the automotive has a camera connected to the computer in which the visual stimuli are superimposed. They use three rectangles that emit signals at $13-15 \mathrm{~Hz}$. The system captures the signals using a bioamplifier, then converts the analog signals to digital ones and finally they are processed to control the RC car. Similarly, Wu et al. (2016) shows a BCI system that controls an RC car inside a labyrinth; one of the objectives of the research is to get a system that avoids obstacles. The system uses a NuAmp EEG amplifier and a remote control car that uses four types of signals i.e., 7 , 8-10 $\mathrm{Hz}$ for its movements i.e. go forward, turn to the left, turn to the right and go backwards, respectively. The operation of the system is based on receiving signals through the NuAmp amplifier which are produced by a visual stimulus generated on a screen. These signals are passed through a fourth order bandpass filter with Low cutoff frequency (Lf1) and High cutoff frequency (Hf1) in order to remove the noise.
Persisting in the automotive control field, Farmaki et al. (2016) presents a BCI System based on SSVEP responses that control an RC car using 4 commands: move forward, turn left, turn right and brake. Commands are sent when an SSVEP response is received at different frequencies (10 Hz for "go forward", 13,333 $\mathrm{Hz}$ for "turn right”, $15 \mathrm{~Hz}$ for "turn left”, brake when no stimulus is received). In the same way, GonzalezMendoza et al. (2015) describes the development of an SSVEP system that controls a car remotely. For the control of the movements of the car, an interface of 4 visual stimuli zones was developed (15 $\mathrm{cm} 2$ each zone) and each zone generates 4 different visual stimuli $9 \mathrm{~Hz}$ (to advance), 8 (to go back), 7 (turn left) and $6 \mathrm{~Hz}$ (turn right). After obtaining and processing the signal, an algorithm proposed by the researchers was used to find the peak of the power spectrum of second harmonic; if the peak is at the frequency corresponding to the visual stimulus, the interface proceeds to send the respective command to move the car via Bluetooth communication; the system makes use of an Arduino board and a full bridge controller L298N for motor controlling.

Furthermore, two SSVEP BCI systems created to control an MRC (Mobile Robotic Car) are found in our literature review. Liu et al. (2018) proposes a BCI system that uses 4 stimuli frequencies $(18 \mathrm{~Hz}$ to turn left, $20 \mathrm{~Hz}$ to move forward, $22 \mathrm{~Hz}$ to turn right and $24 \mathrm{~Hz}$ to move back). The system uses a GES 300 system with a 64-channel hat, a smart Wi-Fi car that uses an Arduino microcontroller with an ultrasonic sensor and a camera that presents the environment in real time. LEDs were used to generate the stimuli. Similarly, the BCI system proposed by Stawicki et al. (2016) has live video feedback and allows to control the camera and MRC. When you are in driver mode, you have the options to go forward, turn left, turn right and change to camera mode; in camera mode, you have the possibility to look to the left, look to the right, look up and change to driver mode. The frequencies used to control these commands vary from person to person and they are selected using a wizard software which chooses the four best frequencies from a set of 14 possible frequencies (from 6-20 Hz). In the same way, article Zhang et al. (2017a, b) develops a BCI application that allows controlling a mobile unit through the Internet. The platform uses a server for EEG signal acquisition/processing and an integrated robotic arm which is controlled by an Android smartphone using the Bluetooth protocol. The SSVEP system uses 7, 11, 13, 17 and $19 \mathrm{~Hz}$ to represent the turn left, turn right, advance, move back, move the robotic commands, respectively.

Robot control: In 1929, Berger demonstrated the possibility of recording brainwaves from the intact skull. Since, then, researchers have tried to use those signals for 
different purposes in different areas. In this sense, one of the most active areas of brainwaves application now a days is the field of robotics, since, they can deeply transform the lifestyle and way of working of people around the world.

Within the reviewed articles, Guneysu and Akin (2013) shows a BCI system that uses SSVEP responses to control a humanoid robot NAO. The SSVEP system uses 7, 9, 11, $15 \mathrm{~Hz}$ lights to move left, right, down and up, mainly emitted from 4 light-emitting diodes. The mentioned articles maintain a similarity with Zhao et al. (2017) which uses a BCI system with SSVEP responses to control an NAO robot. The system uses 5 frequencies between 4.615, 6.67, 8.57, 12, 15 and $20 \mathrm{~Hz}$. SSVEP to navigate through menus with the help of a graphical interface. This will allow the user to implement 14 different behaviors through the use of enhanced frequency stimuli.

On the other hand, Kang et al. presents a method to control robots using EEG-SSVEP. Although, the researchers indicate that they are controlling robots in the background, the system controls only the leading robot while the rest devices move through a "follow the leader" paradigm. To generate the stimuli, a $1020 \times 580$ screen is used to display 4 rectangles $(10 \times 8 \mathrm{~cm}$ each) with frequencies of $8.75,10,12$ and $15 \mathrm{~Hz}$ corresponding to move back, turn clockwise, turn anticlockwise and move along commands. The system is constructed in such a way that the EEG waves are extracted using the NCC NuAmps of 24 channels at a sampling rate of $512 \mathrm{~Hz}$.

Finally, Su and Li (2017) presents a BCI system based on SSVEP that control a humanoid robot moving within a space containing static and dynamic obstacles. The system uses Kinect and laser sensors to obtain a map of the space where the robot will be mobilized and such data is stored in the FastSLAM program. Subsequently, the brainwaves are captured by using the NeuroScan EEG and they are classified in different commands e.g., there is no obstacle, brake, obstacle to the right and obstacle to the left; commands to avoid obstacles use the Probability Potential Field (PPF).

Internet of things: The growing number of devices connected to the Internet has contributed to the development and implementation of new technologies such as smart homes, smart industries and smart cities. In this situation, the scientific community has also begun to develop applications that combine Internet of Things (IoT) and BCI technologies. The first BCI solutions to control IoT devices showed up as platforms as seen by De Buyser et al. (2016); Jagadish et al. (2017) and applications by Shivappa et al. (2018). These solutions use brainwaves captured by EEGs and produced by human actions such as blinking and facial expressions. Even though blinking and facial expressions are good options, the use of SSVEP in IoT applications are considered an important advance in the area since, the increase of the quantity of visual stimuli frequencies will generate a greater range of commands to control more variety of devices. This is the reason why several articles are focusing on the control of IoT devices based on SSVEP. Zhao et al. (2017) proposes an SSVEP solution for controlling household devices such as lights and electric curtains; this system makes use of an ADS1299 based headset to extract data generated by 8, 9, 11 and 12 $\mathrm{Hz}$ stimulus frequencies. The headset amplifies the signals to improve accuracy and it is designed to be portable. On the other hand, another SSVEP IoT system is presented by Virdi et al. (2017). In such solution, different IoT devices such as lights, fans, televisions and alarms of a house are controlled by $10-13 \mathrm{~Hz}$ stimulus frequencies. Furthermore, a platform prototype for multiple devices control has been developed by Anindya et al. (2016); the system allows to control up to three connected devices and it uses a low stimulus frequencies set $(6,6.5,7,7.5,8.2,9.3,10,12 \mathrm{~Hz})$ and a high frequencies set $(8,14,28 \mathrm{~Hz})$.

Virtual reality: According to Alimardani et al. (2015), the development of applications in virtual reality has increased considerably due to the growing interest of users and launching of affordable devices. In this aspect, BCI systems have been used for different applications to connect the real world with a virtual one.

Among different applications, SSVEP based BCIs that allow users to explore virtual worlds also have received the attention of the research community. In Bevilacqua et al. (2014), the authors propose an avatar control system (in first person view) which uses 12, 15 and $20 \mathrm{~Hz}$ stimulus frequencies for executing turn left, turn right and go forward commands, respectively. Additionally by Li et al. (2017), the researcher propose a car driving system in a virtual world. The system uses 8 and $10 \mathrm{~Hz}$ SSVEP stimulus frequencies to brake and accelerate the car and uses motor imagery to execute turn left and turn right commands, it also includes a computer vision module to detect intersections and collisions.

Augmentative and alternative communication: Augmentative and Alternative Communication (AAC) refers to any method that allows a person to communicate without the need of talking Augmentative and Alternative Communication (ASHA) (2019). According to Abhang et al. (2016) BCI systems have ventured into this area through the implementation of different techniques such as spellers (e.g., following the Donchin format for the character matrix). One of this type of systems is proposed by Nakanishi et al. (2017). In such system, the authors propose a solution completely based on SSVEP which uses 40 stimuli with frequencies ranging from $8-15.8 \mathrm{~Hz}$ in $0.2 \mathrm{~Hz}$ intervals displayed in a $5 \times 8$ 
matrix, representing 26 characters, 10 digits/numbers and 4 symbols. On the other hand, Won et al. (2014) presents a 30-character speller whose peculiarity is that it uses high frequencies visual stimuli. We are saying that the system is peculiar since, SSVEP systems usually work with a low frequencies range $(<20 \mathrm{~Hz})$. In this research, high frequencies are used since they can reduce the fatigue of the subject and it can make the system less susceptible to external noise. For the system, an LED keyboard with a QWERTY design of $28.5 \times 8.5 \mathrm{~cm}$ was used; the interface contains the $26 \mathrm{~L}$ of the English alphabet and some special characters such as '. ', ' <', ' _ ' and '/'. To assign frequencies, a distribution model was designed for each letter, so, the minimum difference between neighboring LEDs was $1.2 \mathrm{~Hz}$ in a range from 26-34.7 Hz.

\section{RESULTS AND DISCUSSION}

Analysis of technical specifications of previous works methods of data extraction and classification: In BCI systems, stimuli generation and data gathering are characterized and classified based on electrodes location standards. However, signal processing and classification for detecting commands of applications are not subject to any specification or standard. In fact, the effectiveness of these alternatives is one of the main focus of research in the BCI field. Methods for data processing and classification go from traditional signal analysis methods to machine learning algorithms. A summary of the classification methods used in recent researches is organized in Table 1.
Canonical Correlation Analysis (CCA) is an approach that is gaining strength in SSVEP signals detection and differentiation. As you can see in Table 1, CCA was not used a few years ago but it is used in most of the latest research works. This is because unlike other techniques, CCA has a better Signal-to-Noise Ratio (SNR), less subject dependency and allows the use of harmonic frequencies (Hakvoort et al. (2011)); in fact, it is the technique that delivered better results. Additionally, we have noticed that CCA is commonly used in conjunction with other techniques in order to improve its accuracy in non-harmonic frequencies (achieving an average of 81.5\% in terms of precision). Since, traditional techniques usually have the limitation of having low precision in detecting harmonic frequencies, CCA appears as its solution. Additionally, CCA allows making use of a greater number of stimuli which can be translated into more commands for applications.

Even though, CCA is the most used technique in recent years according to the reviewed articles, other traditional methods such as Linear Discriminant Analysis (LDA) or Fast Fourier Transform (FFT) are also widely used. LDA is a very simple linear classifier and its use has become popular due to its low computational complexity (Nicolas-Alonso and Jaime, 2012) for this reason, this technique is used to implement solutions in microcontroller boards with limited resources. In addition, LDA's popularity is due to its acceptable results; the previous works that we have analyzed in this review had an average accuracy of $81.8 \%$. FFT is another popular algorithm and it is used in conjunction with some filters

Table 1: Classification methods used in SSVEP BCI systems

\begin{tabular}{|c|c|c|c|c|}
\hline Application area & References & Articles title & Classification method & Results (accuracy) \\
\hline \multirow[t]{8}{*}{$\begin{array}{l}\text { Health: Manipulation } \\
\text { assistive technologies }\end{array}$} & Peng et al. (2016) & $\begin{array}{l}\text { Control of a nursing bed based on a hybrid } \\
\text { brain-computer interface }\end{array}$ & MEC and SVM & $93.75 \%$ \\
\hline & Perera et al. (2017) & SSVEP Based BMI for a meal assistance robot & FFT & $87.88 \%$ \\
\hline & Perera et al. (2017) & $\begin{array}{l}\text { EEG-controlled meal assistance robot with } \\
\text { camera-based automatic mouth position tracking } \\
\text { and mouth open detection }\end{array}$ & Threshold based & $85.7,100$ and $85.7 \%$ \\
\hline & $\begin{array}{l}\text { Ruhunage et al. } \\
\text { (2017) }\end{array}$ & $\begin{array}{l}\text { EMG signal controlled transhumeral prosthetic with } \\
\text { EEG-SSVEP based approach for hand open/close }\end{array}$ & Threshold based & $90.90 \%$ \\
\hline & Zhang et al. (2017) & A hybrid EEG-based BCI for robot grasp controlling & CCA and LR-LDS & $66.46 \%$ \\
\hline & Zhang et al. (2011) & $\begin{array}{l}\text { A new object-oriented SSVEP-based BCI paradigm } \\
\text { using continuous action scene }\end{array}$ & CCA & $87.66 \pm 2.09 \%$ \\
\hline & Pelayo et al. (2018) & $\begin{array}{l}\text { Brain-computer interface controlled robotic arm } \\
\text { to improve quality of life }\end{array}$ & Not specified & $85.86 \%$ \\
\hline & Yang et al. (2017) & $\begin{array}{l}\text { Mind control of a robotic arm with visual fusion } \\
\text { technology }\end{array}$ & FFT and CCA & $90 \%$ \\
\hline \multirow[t]{5}{*}{$\begin{array}{l}\text { Health: Navigation } \\
\text { assistive technologies }\end{array}$} & Li et al. (2013) & $\begin{array}{l}\text { A hybrid BCI system combining P300 and } \\
\text { SSVEP and its application to wheelchair control }\end{array}$ & MEC and SVM & Not specified \\
\hline & $\begin{array}{l}\text { Turnip et al. } \\
\text { (2015a-c) }\end{array}$ & $\begin{array}{l}\text { EEG-SSVEP signals extraction with nonlinear } \\
\text { adaptive filter for brain-controlled wheelchair }\end{array}$ & NAF and ANFIS & $95 \%$ \\
\hline & $\begin{array}{l}\text { Andronicus et al. } \\
\text { (2015) }\end{array}$ & $\begin{array}{l}\text { Heuristic steady state visual evoked potential } \\
\text { based brain computer interface system for robotic } \\
\text { wheelchair application }\end{array}$ & $\begin{array}{l}\text { Threshold and } \\
\text { voting system }\end{array}$ & $84.94 \%$ \\
\hline & Turnip et al. (2016) & $\begin{array}{l}\text { An application of online ANFIS classifier for } \\
\text { wheelchair based brain computer interface }\end{array}$ & ANFIS & $90 \%$ \\
\hline & Turnip et al. (2017) & $\begin{array}{l}\text { Real time classification of SSVEP brain activity } \\
\text { with adaptive feedforward neural networks }\end{array}$ & AFNN & $85 \%$ \\
\hline
\end{tabular}


J. Eng. Applied Sci., 15 (2): 659-678, 2020

Table 1: Continue Application area

\begin{tabular}{ll} 
References & Articles title \\
\hline Turnip et al. (2017) & $\begin{array}{l}\text { Design of extraction method of ssvep brain activity } \\
\text { with IIR chebyshev }\end{array}$ \\
Turnip et al. (2016) & $\begin{array}{l}\text { Utilization of EEG-SSVEP method and ANFIS } \\
\text { classifier for controlling electronic wheelchair } \\
\text { An SSVEP based brain computer interface system } \\
\text { to control electric wheelchairs }\end{array}$ \\
Achic et al. (2016) & $\begin{array}{l}\text { Hybrid BCI system to operate an electric wheelchair } \\
\text { and a robotic arm for navigation and manipulation tasks }\end{array}$ \\
Gui et al. (2015) & $\begin{array}{l}\text { Online brain-computer interface controlling robotic } \\
\text { exoskeleton for gait rehabilitation }\end{array}$ \\
Savic and Popovic & $\begin{array}{l}\text { Brain computer interface prototypes for upper limb } \\
\text { Rehabilitation: a review of principles and } \\
\text { experimental results }\end{array}$
\end{tabular}

Lee et al. (2012)

A brain-wave-actuated small robot car using ensemble empirical mode decomposition-based approach

Vehicles: UGV

Health: Hybrid assistive technologies Health: Physical rehabilitation

Control

Vehicles: UAV

control

Robotics

Virtual reality

Internet of things

Augmentative and Alternative

Communication

(AAC) Zhang et al. (2012) A simple platform of brain-controlled mobile robot

Diez et al. (2014) Mobile robot navigation with a self-paced brain-computer interface based on high-frequency SSVEP

Farmaki et al. Applicability of SSVEP-based brain-computer (2016) interfaces for robot navigation in real environments

Gonzalez-Mendoza Brain Computer Interface based on SSVEP for et al. (2015) Stawicki et al. (2016)

Su and $\mathrm{Li}(2017)$ controlling a remote control car Driving a semiautonomous mobile robotic car controlled by an SSVEP-Based BCI Brain-computer interface based stochastic navigation and control of a semiautonomous mobile robot in an indoor environment

Wu et al. (2010) A new SSVEP based BCI application on the mobile robot in a maze game

Brain-machine interfacing-based teleoperation of multiple coordinated mobile robots

Liu et al. (2016) Design of a video feedback SSVEP-BCI system for car control based on improved MUSIC method

Khan et al. (2017) Hybrid EEG-NIRS based active command generation for quadcopter movement control

Wang et al. (2018) A Wearable SSVEP-Based BCI system for quadcopter control using head-mounted device Guneysu and Akin An SSVEP based BCI to control a humanoid (2013) Zhao et al. (2017) Behavior-based SSVEP hierarchical architecture for telepresence control of humanoid robot to achieve full-body movement

Bevilacqua et al. A novel BCI-SSVEP based approach for control (2014)

of walking in virtual environment using a convolutional neural network

A human-vehicle collaborative simulated driving system based on hybrid brain-computer interfaces and computer vision

Anindya et al. A prototype of SSVEP-based BCI for home (2016) appliances control

Zhao et al. (2017) A ASVEP intelligent home service system based on CCA

Virdi et al. (2017) Home automation control system implementation using SSVEP based brain-computer interface

Won et al. (2014) A BCI speller based on SSVEP using high frequency sStimuli design

Nakanishi et al. (2017)
Classification method $\quad$ Results (accuracy)

$\begin{array}{ll}\text { AFNN } & 82 \% \\ \text { ANFIS } & 90 \%\end{array}$

SNR base

79.4 and $100 \%$

Linear $\quad 79 \%$

LDA $\quad 92.40 \%$

Not specified $\quad 79.17,100$ and $79.5 \%$

MFD

$94.74 \%$

CCA and LDA $\quad 71.70 \%$

FFT

$87.40 \%$

CCA and LDA $\quad 70 \%$

FFT $\quad 70 \%$

MEC $\quad 93.03 \%$

MSI $\quad 94.08 \%$

FFT $\quad 83.83 \%$

LDA $\quad 84.80 \%$

MUSIC and SVM $\quad 87.50 \%$

LDA $\quad 87.20 \%$

CCA $\quad 83.33 \%$

DFT and a Gaussian $\quad 75 \%$

model

CCA $\quad 88 \%$

CNN $\quad 87.50 \%$

CCA, wCCA, CSP, $\quad 91.1 \pm 10.0 \%$ kNN and SVM

SVM

83.26 y $71.67 \%$

CCA

$87 \%$

LDA

$84.80 \%$

CCA

$80 \%$

TRCA

$89.83 \pm 6.07 \%$ 
in the signal pre-processing phase; the works using FFT that we analyzed in this review had an average accuracy of $82.4 \%$.

Another important fact is that the presence of machine learning and deep learning techniques is increasing significantly. The use of Support Vector Machine (SVM) and neural networks such as Convolutional Neural Network (CNN) or Adaptive Feedforward Neural Network (AFNN) in classification tasks is increasing due to their results in terms of accuracy (average accuracy of $85.6 \%$ in reviewed articles). With this background, machine learning techniques seem to be promising options to achieve more precise results with less subject dependency in the future. However, we must consider that the implementation of these technologies requires wider knowledge to adjust its parameters and a larger amount of data/time to train and test the models.

Used channels: One of the most important information in BCI applications is the channels used to gather brain signals since, they are the source of input data. Because of such importance, this review also has analyzed the different channels used in different researches. Our analysis indicated that channels $\mathrm{O} 1, \mathrm{O} 2$ and $\mathrm{Oz}$ were the most frequently used in SSVEP (Meng et al., 2011). This is because these channels are located in the occipital lobe of the brain which is involved with vision. As shown in Table 2 among 43 articles, 27 of them used the $\mathrm{Oz}$ channel while 30 used $\mathrm{O} 1$ or 2 as a solitary channel or in combination with other channels. It should also be noted that 31 of the articles used channels different from those indicated above; we assume that this was due to:

Restriction of channels: The following articles Guneysu and Akin (2013); Gui et al. (2015); Achic et al. (2016); Wang et al. (2018) make use of EMOTIV EPOC that has 14 channels that include $\mathrm{O} 1$ and 2 but does not have the Oz channel.

Variation of signals: SSVEP varies depending on the user Meng et al. (2011).

Hybrid solution: Some articles such as Peng et al. (2016); Zhang et al. (2017); Li et al. (2017) implements a hybrid BCI system that incorporates SSVEP in combination with other method such as motor imagery and P300.

Within the reviewed articles, 3 did not specify the used channels as seen in Yang et al. (2017); Zhao et al. (2016a, b) and Pelayo et al. (2018) specified the number of used channels.

Evaluation methods: Each system needs an evaluation process to determinate its level of accuracy. In this regard, we believe that it is important to understand which are the most popular methods used by different works in evaluating BCI systems, to obtain reproducible and quantifiable measurements. In this review, we have analyzed which are the most popular evaluation methods used in different articles. This analysis will help researchers to recognize the possible evaluation methods for this kind of systems. Table 3 shows that the most used metric is the success rate which presents the percentage of success with respect to the errors that existed during the tests. Another common evaluation criteria is the time efficiency.

Participants: Reviewing different articles of the BCI field, we understand that the accuracy achieved by the proposed models is a very important metric (summarized in Table 1). But these results are be insufficient to determine the reliability of a system as a real-life solution if it were tested in a small number of users; this is because one of the main problems of BCI systems on detecting and classifying signals is the subject's dependency. For this reason, an analysis of testing environments of reviewed articles was carried out in this review.

Table 4 presents the number of subjects who participated in the experimentation of previous articles. It reflects that among the 40 reviewed articles, only Liu et al. (2018) does not show concise information in this aspect. The research in which the largest number of experimental subjects has participated was in Stawicki et al. (2016) with 61 people and it was the article that obtained one of the best results (with an accuracy of $93.03 \%$ ). The articles that have tested with the smallest number of subjects were in GonzalezMendoza et al. (2015) and Yang et al. (2017) with 2 people each. The most common number of participants in experiments were 4 people (present in 10 of the reviewed articles) while the average number of participants was 7.95 .

BCI equipment: In this review, we also have analyzed the equipment used by researchers in developing their experimental prototypes. The information gathered in this analysis is organized in Table 5. Such table indicates that Li et al. (2013); Peng et al. (2016); Su and Li (2017); Wu et al. (2016); Yang et al. (2017); Zhang et al. (2017a, b); Nakanishi et al. (2017) and Wang et al. (2018) have used BCI hardware made by NeuroScan (from different models). Similarly, OpenBCI and Emotiv EPOC also demonstrate to be a popular solution with 5 articles each. On the other hand, other articles such as Turnip et al. (2015a-c); Andronicus et al. (2015); Turnip et al. (2016); Anindya et al. (2016)and Turnip et al. (2017)did not specify the BCI hardware that they used.

Additionally, we could observe that 19 of the articles used an EEG electrode cap; although, the articles did not detail the model, the information was inferred using the 
Table 2: Channels used in the reviewed articles

\begin{tabular}{|c|c|c|c|}
\hline References & Articles title & No. of channels & Channels \\
\hline Turnip et al. (2015a-c) & $\begin{array}{l}\text { EEG-SSVEP signals extraction with nonlinear adaptive filter for } \\
\text { brain-controlled wheelchair }\end{array}$ & 3 & $\mathrm{O} 1, \mathrm{O} 2, \mathrm{Pz}$ \\
\hline Turnip et al. (2016) & $\begin{array}{l}\text { Utilization of EEG-SSVEP method and ANFIS classifier for } \\
\text { controlling electronic wheelchair }\end{array}$ & 3 & $\mathrm{O} 1, \mathrm{O} 2, \mathrm{Pz}$ \\
\hline Turnip et al. (2017) & $\begin{array}{l}\text { Real time classification of SSVEP brain activity with adaptive } \\
\text { feedforward neural networks }\end{array}$ & 3 & $\mathrm{O} 1, \mathrm{O} 2, \mathrm{Oz}$ \\
\hline Turnip et al. (2017) & $\begin{array}{l}\text { Design of extraction method of SSVEP brain activity with IIR } \\
\text { chebyshev }\end{array}$ & 3 & $\mathrm{O} 1, \mathrm{O} 2, \mathrm{Oz}$ \\
\hline Achic et al. (2016) & $\begin{array}{l}\text { Hybrid BCI system to operate an electric wheelchair and a robotic } \\
\text { Arm for navigation and manipulation Tasks }\end{array}$ & 4 & P7, O1, O2, P8 \\
\hline Andronicus et al. (2015) & $\begin{array}{l}\text { Heuristic steady state visual evoked potential based brain computer } \\
\text { interface system for robotic wheelchair application }\end{array}$ & 1 & $\mathrm{Oz}$ \\
\hline Anindya et al. (2016) & A prototype of SSVEP-based BCI for home appliances control & 4 & $\mathrm{O} 1, \mathrm{O} 2, \mathrm{POz}, \mathrm{Oz}$ \\
\hline Bevilacqua et al. (2014) & $\begin{array}{l}\text { A novel BCI-SSVEP based approach for control of walking in } \\
\text { virtual environment using a convolutional neural network }\end{array}$ & 6 & $\mathrm{Cz}, \mathrm{Pz}, \mathrm{PO} 3, \mathrm{PO} 4, \mathrm{Oz}, \mathrm{AFz}$ \\
\hline Zhang et al. (2012) & $\begin{array}{l}\text { A simple platform of brain-controlled mobile robot and its } \\
\text { implementation by SSVEP }\end{array}$ & 4 & $\mathrm{Oz}, \mathrm{O} 1, \mathrm{O} 2, \mathrm{Pz}$ \\
\hline Diez et al. (2014) & $\begin{array}{l}\text { Mobile robot navigation with a self-paced brain-computer interface } \\
\text { based on high-frequency SSVEP }\end{array}$ & 3 & $\mathrm{O} 1, \mathrm{Oz}, \mathrm{O} 2$ \\
\hline $\begin{array}{l}\text { González-Mendoza } \\
\text { et al. (2015) }\end{array}$ & $\begin{array}{l}\text { Brain computer interface based on SSVEP for controlling a remote } \\
\text { control car }\end{array}$ & 2 & $\mathrm{Fz}, \mathrm{Oz}$ \\
\hline Gui et al. (2015) & $\begin{array}{l}\text { Online brain-computer interface controlling robotic exoskeleton for } \\
\text { gait rehabilitation }\end{array}$ & 4 & $\mathrm{O} 1, \mathrm{O} 2, \mathrm{PO} 3, \mathrm{PO} 4$ \\
\hline $\begin{array}{l}\text { Guneysu and Akin } \\
\text { (2013) }\end{array}$ & $\begin{array}{l}\text { An SSVEP based BCI to control a humanoid robot by using portable } \\
\text { EEG device }\end{array}$ & 1 & $\mathrm{O} 1, \mathrm{O} 2$ \\
\hline Zhao et al. (2017) & $\begin{array}{l}\text { Behavior-based SSVEP hierarchical architecture for telepresence } \\
\text { control of humanoid robot to achieve full-body movement }\end{array}$ & 9 & $\begin{array}{l}\text { Oz, POz, PO3, PO4, PO5, } \\
\text { PO6, Pz, P1, P2 }\end{array}$ \\
\hline Kang et al.(2016) & $\begin{array}{l}\text { Brain-machine interfacing-based teleoperation of multiple } \\
\text { coordinated mobile robots }\end{array}$ & 24 & $\begin{array}{l}\text { SP1, SP2, FP1, FP2, F7, F3, } \\
\text { FZ, F4, F8, T3, C3, CZ, } \\
\text { C4, T4, T5, P3, PZ, P4, } \\
\text { T6, REF, O1, Oz, O2, } \\
\text { GND }\end{array}$ \\
\hline Khan et al.(2016) & $\begin{array}{l}\text { Hybrid EEG-NIRS based active command generation for quadcopter } \\
\text { movement control }\end{array}$ & 14 & $\begin{array}{l}\text { F3, AF4, F3, F4, F7, F8, FC5 } \\
\text { FC6, T7, T8, P7, P8, O1, } \\
\text { O2 }\end{array}$ \\
\hline Zhang et al. (2011) & $\begin{array}{l}\text { A new object-oriented SSVEP-based BCI paradigm using } \\
\text { continuous action scene }\end{array}$ & 6 & $\mathrm{PO} 3, \mathrm{Pz}, \mathrm{PO} 4, \mathrm{O} 1, \mathrm{Oz}, \mathrm{O} 2$ \\
\hline Lakmazaheri et al. & $\begin{array}{l}\text { Applicability of SSVEP-based brain-computer interfaces } \\
\text { for robot navigation in real environments }\end{array}$ & 4 & $\mathrm{O} 1, \mathrm{O} 2, \mathrm{Oz}, \mathrm{POz}$ \\
\hline Lee et al. (2012) & $\begin{array}{l}\text { A brain-wave-actuated small robot car using ensemble } \\
\text { empirical mode decomposition-based approach }\end{array}$ & 1 & $\mathrm{Oz}$ \\
\hline Li et al. (2018) & $\begin{array}{l}\text { A human-vehicle collaborative simulated driving system based } \\
\text { on hybrid brain-computer interfaces and computer vision }\end{array}$ & 13 & $\begin{array}{l}\text { T7, T8, P7, P8, FC3, FC4, } \\
\mathrm{C} 3, \mathrm{C} 4, \mathrm{CP} 3, \mathrm{CP} 4, \mathrm{P} 3, \mathrm{P} 4 \text {, } \\
\mathrm{Oz}\end{array}$ \\
\hline Liu et al. (2018) & $\begin{array}{l}\text { Design of a video feedback SSVEP-BCI system for car } \\
\text { control based on improved MUSIC method }\end{array}$ & 3 & $\mathrm{O} 1, \mathrm{Oz}, \mathrm{O} 2$ \\
\hline Turnip et al. (2016) & $\begin{array}{l}\text { An application of online ANFIS classifier for wheelchair based brain } \\
\text { computer interface }\end{array}$ & 3 & $\mathrm{O} 1, \mathrm{O} 2, \mathrm{Pz}$ \\
\hline Wang et al. (2018) & $\begin{array}{l}\text { A Wearable SSVEP-Based BCI System for quadcopter } \\
\text { Control Using Head-Mounted Device }\end{array}$ & 6 & $\mathrm{PO} 3, \mathrm{PO} 4, \mathrm{O} 1, \mathrm{O} 2, \mathrm{C} 5, \mathrm{C} 6$ \\
\hline Mistry et al. (2018) & $\begin{array}{l}\text { An SSVEP based brain computer interface system to control } \\
\text { electric wheelchairs }\end{array}$ & 6 & P3, Pz, P4, O1, Oz, O2 \\
\hline Nakanishi et al. (2017) & $\begin{array}{l}\text { Enhancing detection of SSVEPs for a high-speed brain } \\
\text { speller using task-related component analysis }\end{array}$ & 10 & $\begin{array}{l}\mathrm{Pz}, \mathrm{PO} 5, \mathrm{PO} 3, \mathrm{POz}, \mathrm{PO} 4 \\
\mathrm{PO} 6, \mathrm{O} 1, \mathrm{Oz}, \mathrm{O} 2, \mathrm{Cz}\end{array}$ \\
\hline Pelayo et al. (2018) & $\begin{array}{l}\text { Brain-Computer Interface Controlled Robotic Arm to Improve } \\
\text { Quality of Life }\end{array}$ & 6 & Not specified \\
\hline Peng et al. (2016) & Control of a nursing bed based on a hybrid brain-computer interface & 8 & $\begin{array}{l}\text { P7, P3, Pz, P4, P8, O1, Oz, } \\
\text { O2 }\end{array}$ \\
\hline Perera et al. (2016) & $\begin{array}{l}\text { EEG-controlled meal assistance robot with camera-based automatic } \\
\text { mouth position tracking and mouth open detection }\end{array}$ & 8 & $\begin{array}{l}\mathrm{O} 1, \mathrm{O} 2, \mathrm{POz}, \mathrm{PO} 3, \mathrm{PO} 4 \\
\mathrm{C} 1, \mathrm{C} 2, \mathrm{C} 3\end{array}$ \\
\hline Perera et al. (2017) & SSVEP Based BMI for a meal assistance robot & 8 & $\begin{array}{l}\mathrm{O} 1, \mathrm{O} 2, \mathrm{POz}, \mathrm{PO} 3, \mathrm{PO} 4 \\
\mathrm{C} 1, \mathrm{C} 2, \mathrm{C} 3\end{array}$ \\
\hline Zhao et al. (2017) & A SSVEP intelligent home service system based on CCA & Not specified & Not specified \\
\hline Ruhunage et al. (2017) & $\begin{array}{l}\text { EMG signal controlled transhumeral prosthetic with } \\
\text { EEG-SSVEP based approach for hand open/close }\end{array}$ & 2 & $\mathrm{POz}, \mathrm{Oz}$ \\
\hline Savic and Popovic (2015) & $\begin{array}{l}\text { Brain computer interface prototypes for upper limb } \\
\text { Rehabilitation: a review of principles and experimental results }\end{array}$ & 3 & $\mathrm{C} 3, \mathrm{Oz}, \mathrm{Cz}$ \\
\hline
\end{tabular}


Table 2: Continue

\begin{tabular}{|c|c|c|c|}
\hline References & Articles title & No. of channels & Channels \\
\hline Stawicki et al.(2016) & $\begin{array}{l}\text { Driving a Semiautonomous Mobile Robotic Car Controlled by an } \\
\text { SSVEP-Based BCI }\end{array}$ & 10 & $\begin{array}{l}\mathrm{Pz}, \mathrm{PO}, \mathrm{PO} 4, \mathrm{O} 1, \mathrm{O} 2, \mathrm{Oz} \\
\mathrm{O}, \mathrm{O} 10, \mathrm{AFz}, \mathrm{Cz}\end{array}$ \\
\hline Su and $\mathrm{Li}(2017)$ & $\begin{array}{l}\text { Brain-computer interface based stochastic navigation and control } \\
\text { of a semiautonomous mobile robot in an indoor environment }\end{array}$ & 4 & $\mathrm{PZ}, \mathrm{O} 1, \mathrm{Oz}, \mathrm{O} 2$ \\
\hline Virdi et al. (2017) & $\begin{array}{l}\text { Home automation control system implementation using } \\
\text { SSVEP based brain-computer interface }\end{array}$ & 8 & $\begin{array}{l}\text { PO7, PO3, PO4, POz, PO8, } \\
\text { O1, O2, Oz }\end{array}$ \\
\hline Zhang et al. (2016) & A hybrid EEG-based BCI for robot grasp controlling & 8 & $\begin{array}{l}\text { P7, P3, Pz, P4, P8, O1, Oz, } \\
\text { O2 }\end{array}$ \\
\hline Won et al. (2014) & A BCI Speller based on SSVEP using high frequency stimuli design & 15 & $\begin{array}{l}\text { P5, P3, P1, Pz, P2, P4, P6, } \\
\text { PO7, PO3, POz, PO4, PO8, } \\
\text { O1, Oz, O2 }\end{array}$ \\
\hline Wu et al. (2016) & $\begin{array}{l}\text { A new SSVEP based BCI application on the mobile robot in a maze } \\
\text { game }\end{array}$ & 4 & $\mathrm{O} 1, \mathrm{Oz}, \mathrm{O} 2, \mathrm{Pz}$ \\
\hline Yang et al. (2017) & Mind control of a robotic arm with visual fusion technology & 6 & $\mathrm{O} 1, \mathrm{O} 2, \mathrm{Oz}, \mathrm{P} 3, \mathrm{P} 4, \mathrm{Pz}$ \\
\hline Li et al. (2013) & $\begin{array}{l}\text { A hybrid BCI system combining P300 and SSVEP and its application } \\
\text { to wheelchair control }\end{array}$ & 8 & P7, P3, Pz, P4, P8, O1, Oz,O2 \\
\hline
\end{tabular}

Table 3: Metrics used to evaluate system's performance

\begin{tabular}{lll}
\hline Reference & Articles Title & Evaluation metric \\
\hline Turnip et al. (2015a-c) & $\begin{array}{l}\text { EEG-SSVEP signals extraction with nonlinear adaptive filter for brain-controlled } \\
\text { wheelchair }\end{array}$ & Success rate \\
Turnip et al. (2016) & $\begin{array}{l}\text { Utilization of EEG-SSVEP method and ANFIS classifier for controlling electronic } \\
\text { wheelchair }\end{array}$ & Success rate
\end{tabular}

Turnip et al. (2017) Real time classification of SSVEP brain activity with adaptive feedforward neural

Success rate networks

Turnip et al. (2017)

Design of extraction method of ssvep brain activity with iir chebyshev

Achic et al.(2016) Hybrid BCI system to operate an electric wheelchair and a robotic arm for navigation and manipulation tasks

Andronicus et al. (2015) Heuristic steady state visual evoked potential based brain computer interface system for robotic wheelchair application

Anindya et al. (2016) A prototype of SSVEP-based BCI for home appliances control

Bevilacqua et al. (2014) A novel BCI-SSVEP based approach for control of walking in virtual environment using a convolutional neural network

Zhang et al. (2012) A simple platform of brain-controlled mobile robot and its implementation by SSVEP

Diez et al. (2014) Mobile robot navigation with a self-paced brain-computer interface based on high-frequency SSVEP

Gonzalez-Mendoza et al. Brain Computer Interface based on SSVEP for controlling a remote control car

(2015)

Gui et al.(2015) Online brain-computer interface controlling robotic exoskeleton for gait rehabilitation

Success rate

Success rate and time efficiency

Success rate

Success rate

Success rate

Success rate and information transfer rate

Success rate and time efficiency

Success rate

Duration of the transitional state and rate of recognition of the steady state

Success rate

Guneysu and Akin (2013) An SSVEP based BCI to control a humanoid robot by using portable EEG device

Success rate and time efficiency

Zhao et al.(2017)

Behavior-based SSVEP hierarchical architecture for telepresence control of humanoid robot to achieve full-body movement

Kang et al.

Khan et al. (2016)

Zhang et al.(2011)

Brain-machine interfacing-based teleoperation of multiple coordinated mobile robots

Hybrid EEG-NIRS based active command generation for quadcopter movement control Success rate

Lakmazaheri et al.

Applicability of SSVEP-based brain-computer interfaces for robot navigation

Success rate and time efficiency in real environments

Lee et al. (2012)

A brain-wave-actuated small robot car using ensemble empirical mode decomposition-based approach

Li et al. (2017)

A human-vehicle collaborative simulated driving system based on hybrid brain-computer interfaces and computer vision

Liu et al. (2018)

Design of a video feedback SSVEP-BCI system for car control based on improved MUSIC method

Turnip et al. (2016)

An application of online ANFIS classifier for wheelchair based brain computer interface

Wang et al. (2018) A wearable SSVEP-based BCI system for quadcopter control using head-mounted device

Mistry et al. (2018)

An SSVEP based brain computer interface system to control electric wheelchairs

Nakanishi et al. (2017)

Enhancing detection of SSVEPs for a high-speed brain speller using

Success rate

Command transfer interval, information transfer rate and success rate

T-test, success rate and time efficiency

Success rate

Success rate

Online accuracy, success rate, time efficiency and information transfer rate

Success rate and time efficiency task-related component analysis 
Table 3: Continue

\begin{tabular}{|c|c|c|}
\hline References & Articles title & Evaluation metric \\
\hline Pelayo et al. (2018) & Brain-computer interface controlled robotic arm to improve quality of life & Success rate \\
\hline Peng et al. (2016) & Control of a nursing bed based on a hybrid brain-computer interface & $\begin{array}{l}\text { Success rate, time efficiency and } \\
\text { false-positive rate }\end{array}$ \\
\hline Perera et al. (2017) & $\begin{array}{l}\text { EEG-controlled meal assistance robot with camera-based automatic mouth position } \\
\text { tracking and mouth open detection }\end{array}$ & Efficiency of time \\
\hline Perera et al. (2017) & SSVEP Based BMI for a meal assistance robot & Success rate and time efficiency \\
\hline Zhao et al. (2017) & A SSVEP intelligent home service system based on CCA & Success rate \\
\hline Ruhunage et al. (2017) & $\begin{array}{l}\text { EMG signal controlled transhumeral prosthetic with EEG-SSVEP based } \\
\text { approach for hand open/close }\end{array}$ & Success rate and time efficiency \\
\hline Savic and Popovic (2015) & $\begin{array}{l}\text { Brain computer interface prototypes for upper limb rehabilitation: a review of } \\
\text { principles and experimental results }\end{array}$ & Success rate and time efficiency \\
\hline Stawicki et al. (2016) & Driving a semiautonomous mobile robotic car controlled by an SSVEP-Based BCI & $\begin{array}{l}\text { Success rate and information } \\
\text { transfer rate }\end{array}$ \\
\hline Su and Li (2017) & $\begin{array}{l}\text { Brain-computer interface based stochastic navigation and control of a } \\
\text { semiautonomous mobile robot in an indoor environment }\end{array}$ & $\begin{array}{l}\text { ERA, success rate and time } \\
\text { efficiency }\end{array}$ \\
\hline Virdi et al. (2017) & $\begin{array}{l}\text { Home automation control system implementation using SSVEP based } \\
\text { brain-computer interface }\end{array}$ & Success rate and time efficiency \\
\hline Zhang et al. (2017) & A hybrid EEG-based BCI for robot grasp controlling & Success rate and time efficiency \\
\hline Won et al.(2014) & A BCI speller based on SSVEP using high frequency stimuli design & Subjective fatigue and success rate \\
\hline Wu et al. (2016) & A new SSVEP based BCI application on the mobile robot in a maze game & Success rate \\
\hline Yang et al. (2017) & Mind control of a robotic arm with Visual fusion technology & Success rate \\
\hline Li et al. (2013) & $\begin{array}{l}\text { A hybrid BCI system combining P300 and SSVEP and Its } \\
\text { application to wheelchair control }\end{array}$ & $\begin{array}{l}\text { False positives rate and true } \\
\text { positives rate }\end{array}$ \\
\hline
\end{tabular}

Table 4: Number of subjects that participated in system's test

\begin{tabular}{|c|c|c|}
\hline Reference & Articles Title & No.of subjects \\
\hline Turnip et al. (2015a-c) & EEG-SSVEP signals extraction with nonlinear adaptive filter for brain-controlled wheelchair & 4 \\
\hline Turnip et al. (2016) & Utilization of EEG-SSVEP method and ANFIS classifier for controlling electronic wheelchair & 4 \\
\hline Turnip et al. (2017) & Real time classification of SSVEP brain activity with adaptive feedforward neural networks & 11 \\
\hline Turnip et al. (2017) & Design of extraction method of SSVEP brain activity with IIR Chebyshev & 14 \\
\hline Achic et al. (2016) & $\begin{array}{l}\text { Hybrid BCI system to operate an electric wheelchair and a robotic arm for navigation and } \\
\text { manipulation tasks }\end{array}$ & 4 \\
\hline Andronicus et al. (2015) & $\begin{array}{l}\text { Heuristic steady state visual evoked potential based brain computer interface system for } \\
\text { robotic wheelchair application }\end{array}$ & 8 \\
\hline Anindya et al. (2016) & A prototype of SSVEP-based BCI for home appliances control & 4 \\
\hline Bevilacqua et al. (2014) & $\begin{array}{l}\text { A novel BCI-SSVEP based approach for control of walking in virtual environment using } \\
\text { a convolutional neural network }\end{array}$ & 4 \\
\hline Zhang et al. (2012) & A simple platform of brain-controlled mobile robot and its implementation by SSVEP & 4 \\
\hline Diez et al. (2014) & $\begin{array}{l}\text { Mobile robot navigation with a self-paced brain-computer interface based on high-frequency } \\
\text { SSVEP }\end{array}$ & 7 \\
\hline $\begin{array}{l}\text { González-Mendoza et al. } \\
\text { (2015) }\end{array}$ & Brain Computer Interface based on SSVEP for controlling a remote control car & 2 \\
\hline Gui et al. (2015) & Online brain-computer interface controlling robotic exoskeleton for gait rehabilitation & 6 \\
\hline Guneysu and Akin (2013) & An SSVEP based BCI to control a humanoid robot by using portable EEG device & 3 \\
\hline Zhao et al. (2017) & $\begin{array}{l}\text { Behavior-based SSVEP hierarchical architecture for telepresence control of humanoid robot } \\
\text { to achieve full-body movement }\end{array}$ & 5 \\
\hline Kang et al. & Brain-machine interfacing-based teleoperation of multiple coordinated mobile robots & 5 \\
\hline Khan et al. (2016) & Hybrid EEG-NIRS based active command generation for quadcopter movement control & 3 \\
\hline Zhang et al. (2018) & A new object-oriented SSVEP-based BCI paradigm using continuous action scene & 4 \\
\hline Lakmazaheri et al. & Applicability of SSVEP-based brain-computer interfaces for robot navigation in real environments & 15 \\
\hline Lee et al. (2012) & $\begin{array}{l}\text { A brain-wave-actuated small robot car using ensemble empirical mode } \\
\text { decomposition-based approach }\end{array}$ & 11 \\
\hline Li et al. (2013) & $\begin{array}{l}\text { A human-vehicle collaborative simulated driving system based on hybrid brain-computer } \\
\text { interfaces and computer vision }\end{array}$ & 6 \\
\hline Liu et al. (2018) & Design of a video feedback SSVEP-BCI system for car control based on improved MUSIC method & Not specified \\
\hline Turnip et al. (2016) & An application of online ANFIS classifier for wheelchair based brain computer interface & 4 \\
\hline Wang et al. (2018) & A wearable SSVEP-Based BCI system for quadcopter control using head-mounted device & 5 \\
\hline Mistry et al. (2018) & An SSVEP based brain computer interface system to control electric wheelchairs & 4 \\
\hline Nakanishi et al. (2017) & Enhancing detection of SSVEPs for a high-speed brain speller using task-related component analysis & 12 and 20 \\
\hline Pelayo et al. (2018) & Brain-Computer Interface Controlled Robotic Arm to improve quality of Life & 3 \\
\hline Peng et al. (2016) & Control of a nursing bed based on a hybrid brain-computer interface & 8 \\
\hline Perera et al. (2016) & $\begin{array}{l}\text { EEG-controlled meal assistance robot with camera-based automatic mouth position tracking and } \\
\text { mouth open detection }\end{array}$ & 6 \\
\hline Perera et al. (2017) & SSVEP Based BMI for a meal assistance robot & 5 \\
\hline Zhao et al. (2017) & A SSVEP intelligent home service system based on CCA & 10 \\
\hline
\end{tabular}


Table 4: Continue

\begin{tabular}{llr}
\hline References & Articles title & No.of subjects \\
\hline Ruhunage et al. (2017) & $\begin{array}{l}\text { EMG signal controlled transhumeral prosthetic with EEG-SSVEP based approach for hand } \\
\text { open/close }\end{array}$ & 5 \\
Savic and Popovic (2015) & $\begin{array}{l}\text { Brain computer interface prototypes for upper limb rehabilitation: a review of principles and } \\
\text { experimental results }\end{array}$ & 6 \\
Stawicki et al. (2016) & $\begin{array}{l}\text { Driving a semiautonomous mobile robotic car controlled by an SSVEP-Based BCI } \\
\text { brain-computer interface based stochastic navigation and control of a semiautonomous mobile }\end{array}$ & 61 \\
Su and Li (2017) & robot in an indoor environment & 5 \\
Virdi et al. (2017) & Home Automation control system implementation using SSVEP based brain-computer interface & 10 \\
Zhang et al. (2017) & A hybrid EEG-based BCI for robot grasp controlling & 6 \\
Won et al. (2014) & A BCI speller based on SSVEP using high frequency stimuli design & 4 \\
Wu et al. (2016) & A new SSVEP based BCI application on the mobile robot in a maze game & 10 \\
Yang et al. (2017) & Mind control of a robotic arm with visual fusion technology & 2 \\
Li et al. (2013) & A hybrid BCI system combining P300 and SSVEP and Its application to wheelchair control & 8 \\
\hline
\end{tabular}

Table 5: BCI hardware, headset and sensors used in the reviewed articles

\begin{tabular}{|c|c|c|c|c|}
\hline References & Articles title & BCI hardware & Headset & Sensors \\
\hline Turnip et al. (2015a-c) & $\begin{array}{l}\text { EEG-SSVEP signals extraction with nonlinear adaptive } \\
\text { filter for brain-controlled wheelchair }\end{array}$ & Not specified & $\begin{array}{l}\text { EEG Electrode } \\
\text { cap* }\end{array}$ & Not specified \\
\hline Turnip et al. (2016) & $\begin{array}{l}\text { Utilization of EEG-SSVEP method and ANFIS classifier } \\
\text { for controlling electronic wheelchair }\end{array}$ & Not specified & $\begin{array}{l}\text { EEG Electrode } \\
\text { cap* }\end{array}$ & Not specified \\
\hline Turnip et al. (2017) & $\begin{array}{l}\text { Real time classification of SSVEP brain activity with } \\
\text { adaptive feedforward neural networks }\end{array}$ & Not specified* & Not specified & Not specified \\
\hline Turnip et al. (2017) & $\begin{array}{l}\text { Design of extraction method of SSVEP brain activity } \\
\text { with IIR chebyshev }\end{array}$ & Not specified & Not specified & Not specified \\
\hline Achic et al. (2016) & $\begin{array}{l}\text { Hybrid BCI system to operate an electric wheelchair } \\
\text { and a robotic arm for navigation and manipulation tasks }\end{array}$ & Emotiv epoc & Emotiv epoc & $\begin{array}{l}\text { Saline based } \\
\text { electrodes }\end{array}$ \\
\hline $\begin{array}{l}\text { Andronicus et al. } \\
\text { (2015) }\end{array}$ & $\begin{array}{l}\text { Heuristic steady state visual evoked potential based brain } \\
\text { computer interface system for robotic wheelchair application }\end{array}$ & Not specified* & Not specified & Not specified \\
\hline Anindya et al. (2016) & A prototype of SSVEP-based BCI for home appliances control & Not specified & Not specified & Not specified \\
\hline $\begin{array}{l}\text { Bevilacqua et al. } \\
\text { (2014) }\end{array}$ & $\begin{array}{l}\text { A novel BCI-SSVEP based approach for control of walking in } \\
\text { virtual environment using a convolutional neural network }\end{array}$ & g.USBamp & EEG electrode cap* & Not specified \\
\hline Zhang et al. (2012) & $\begin{array}{l}\text { A simple platform of brain-controlled mobile robot and its } \\
\text { implementation by SSVEP }\end{array}$ & MEG61 & Not specified & pecified \\
\hline Diez et al. (2014) & $\begin{array}{l}\text { Mobile robot navigation with a self-paced brain-computer } \\
\text { interface based on high-frequency SSVEP }\end{array}$ & $\begin{array}{l}\text { National } \\
\text { instruments ADC } \\
\text { (NI-DAQPad6015) }\end{array}$ & EEG electrode cap & Not specified \\
\hline $\begin{array}{l}\text { Gonzalez-Mendoza } \\
\text { et al. (2015) }\end{array}$ & $\begin{array}{l}\text { Brain Computer Interface based on SSVEP for controlling a } \\
\text { remote control car }\end{array}$ & $\begin{array}{l}\text { National } \\
\text { instruments ADC } \\
\text { (NI-DAQ 6008) }\end{array}$ & EEG headband * & Not specified \\
\hline Gui et al. (2015) & $\begin{array}{l}\text { Online brain-computer interface controlling robotic } \\
\text { exoskeleton for gait rehabilitation }\end{array}$ & Emotiv epoc & Emotiv epoc & $\begin{array}{l}\text { Saline based } \\
\text { electrodes }\end{array}$ \\
\hline $\begin{array}{l}\text { Guneysu and Akin } \\
\text { (2013) }\end{array}$ & $\begin{array}{l}\text { An SSVEP based BCI to control a humanoid robot by using } \\
\text { portable EEG device }\end{array}$ & Emotiv Epoc & Emotiv Epoc & $\begin{array}{l}\text { Saline Based } \\
\text { electrodes }\end{array}$ \\
\hline Zhao et al. (2017) & $\begin{array}{l}\text { Behavior-based SSVEP hierarchical architecture for } \\
\text { telepresence control of humanoid robot to achieve } \\
\text { full-body movement }\end{array}$ & $\begin{array}{l}\text { CerebusTM } \\
\text { data acquisition } \\
\text { system }\end{array}$ & $\begin{array}{l}\text { EEG electrode } \\
\text { cap }\end{array}$ & Not specified \\
\hline Kang et al. & $\begin{array}{l}\text { chine interfacing-based teleoperation of multiple } \\
\text { ed mobile robots }\end{array}$ & $\begin{array}{l}\text { NCC NuAmps } \\
\text { 24channel }\end{array}$ & Not specified & Not specified \\
\hline Khan et al. (2016) & $\begin{array}{l}\text { Hybrid EEG-NIRS based active command generation for } \\
\text { quadcopter movement control }\end{array}$ & EEG-NIRS* & Not specified & Not specified \\
\hline Zhang et al. (2018) & $\begin{array}{l}\text { A New Object-oriented SSVEP-based BCI paradigm using } \\
\text { continuous action scene }\end{array}$ & $\begin{array}{l}\text { Neusen } \\
\text { amplifier }\end{array}$ & $\begin{array}{l}32 \text { channel } \\
\text { EEG electrode cap }\end{array}$ & Not specified \\
\hline Lakmazaheri et al. & $\begin{array}{l}\text { Applicability of SSVEP-based brain-computer interfaces } \\
\text { for robot navigation in real environments }\end{array}$ & g.MOBIlab & Not specified & Not specified \\
\hline Lee et al. (2012) & $\begin{array}{l}\text { A brain-wave-actuated small robot car using ensemble } \\
\text { empirical mode decomposition-based approach }\end{array}$ & $\begin{array}{l}\text { BioAmp with } \\
\text { national } \\
\text { instruments } \\
\text { ADC } \\
\text { (NI USB-6259) }\end{array}$ & Not specified & Not specified \\
\hline Li et al. (2013) & $\begin{array}{l}\text { A human-vehicle collaborative simulated driving system } \\
\text { based on hybrid brain-computer interfaces and computer vision }\end{array}$ & g.USBmap & EEG electrode cap & Not specified \\
\hline Liu et al. (2018) & $\begin{array}{l}\text { Design of a video feedback SSVEP-BCI system for car control } \\
\text { based on improved MUSIC method }\end{array}$ & $\begin{array}{l}\text { GES } 300 \text { system } \\
\text { adult-sized head cap }\end{array}$ & 64-channel & Not specified \\
\hline Turnip et al. (2016) & $\begin{array}{l}\text { An application of online ANFIS classifier for wheelchair based } \\
\text { brain computer interface }\end{array}$ & Not specified & EEG electrode cap* & Not specified \\
\hline
\end{tabular}


J. Eng. Applied Sci., 15 (2): 659-678, 2020

Table 5: BCI hardware, headset and sensors used in the reviewed articles

\begin{tabular}{|c|c|c|c|c|}
\hline Reference & Articles title & BCI hardware & Headset & Sensors \\
\hline Wang et al. (2018) & $\begin{array}{l}\text { A Wearable SSVEP-Based BCI system for quadcopter control } \\
\text { using head-mounted device }\end{array}$ & Emotiv epoc & Emotiv epoc & $\begin{array}{l}\text { Saline based } \\
\text { Electrodes }\end{array}$ \\
\hline Mistry et al. (2018) & $\begin{array}{l}\text { An SSVEP based brain computer interface system to control } \\
\text { electric wheelchairs }\end{array}$ & OpenBCI V3 & Ultracortex & Diy EEG sensois \\
\hline Nakanishi et al. (2017) & $\begin{array}{l}\text { Enhancing detection of SSVEPs for a high-speed brain speller } \\
\text { using task-related component analysis }\end{array}$ & Synamp 2 system & Synamp 2 system & Not specified \\
\hline Pelayo et al. (2018) & $\begin{array}{l}\text { Brain-computer interface controlled robotic arm to improve } \\
\text { quality of life sensors }\end{array}$ & OpenBCI & Ultracortex & Dry spike EEG \\
\hline Peng et al. (2016) & $\begin{array}{l}\text { Control of a nursing bed based on a hybrid brain-computer } \\
\text { interface }\end{array}$ & $\begin{array}{l}\text { NuAmp EEG } \\
\text { amplifier }\end{array}$ & $\begin{array}{l}\text { EEG Electrode } \\
\text { cap (LT37) }\end{array}$ & $\begin{array}{l}\mathrm{Ag} / \mathrm{AgCl} \\
\text { electrodes }\end{array}$ \\
\hline Perera et al. (2016) & $\begin{array}{l}\text { EEG-controlled meal assistance robot with camera-based } \\
\text { automatic mouth position tracking and mouth open detection }\end{array}$ & OpenBCI V3 & EEG electrode cap* & Not specified \\
\hline Perera et al. (2017) & SSVEP Based BMI for a meal assistance robot & OpenBCI V3 & $\begin{array}{l}\text { Easycap } \\
\text { electrode ca }\end{array}$ & $\begin{array}{l}\text { Gold cup } \\
\text { electrodes }\end{array}$ \\
\hline Zhao et al. (2017) & A SSVEP intelligent home service system based on CCA & ADS1299* & EEG electrode cap* & Not specified \\
\hline Ruhunage et al. (2017) & $\begin{array}{l}\text { EMG signal controlled transhumeral prosthetic with } \\
\text { EEG-SSVEP based approach for hand open/close }\end{array}$ & OpenBCI & EEG electrode cap & Not specified \\
\hline $\begin{array}{l}\text { Savic and Popovic } \\
\text { (2015) }\end{array}$ & $\begin{array}{l}\text { Brain computer interface prototypes for upper limb } \\
\text { rehabilitation: a review of principles and experimental results }\end{array}$ & $\begin{array}{l}\text { PSYLAB } \\
\text { EEG8 }\end{array}$ & $\begin{array}{l}\text { EEG electrode } \\
\text { cap }\end{array}$ & $\begin{array}{l}\mathrm{Ag} / \mathrm{AgCl} \\
\text { electrodes }\end{array}$ \\
\hline Stawicki et al. (2016) & $\begin{array}{l}\text { Driving a semiautonomous mobile robotic car controlled by } \\
\text { an SSVEP-Based BCI }\end{array}$ & Emotiv epoc & Emotiv epoc & $\begin{array}{l}\text { Saline based } \\
\text { electrodes }\end{array}$ \\
\hline Su and Li (2017) & $\begin{array}{l}\text { Brain-Computer interface based stochastic navigation and } \\
\text { control of a semiautonomous mobile robot in an indoor } \\
\text { environment }\end{array}$ & $\begin{array}{l}\text { Neuroscan } \\
\text { amplifier }\end{array}$ & $\begin{array}{l}\text { EEG Electrode } \\
\text { cap }\end{array}$ & Not specified \\
\hline Virdi et al. (2017) & $\begin{array}{l}\text { Home automation control system implementation using } \\
\text { SSVEP based brain-computer interface }\end{array}$ & g.USBamp & G.GAMMAcap & g.LADYbird \\
\hline Zhang et al. (2017) & A hybrid EEG-based BCI for robot grasp controlling & $\begin{array}{l}\text { Neruoscan } \\
\text { EEG system } \\
\text { with } 32 \text { channels }\end{array}$ & $\begin{array}{l}\text { EEG electrode } \\
\text { cap }\end{array}$ & Not specified \\
\hline Won et al. (2014) & $\begin{array}{l}\text { A BCI Speller based on SSVEP using high frequency } \\
\text { stimuli design }\end{array}$ & BrainAmp & EEG electrode cap* & Not specified \\
\hline Wu et al. (2016) & $\begin{array}{l}\text { A new SSVEP based BCI application on the mobile robot } \\
\text { in a maze game }\end{array}$ & $\begin{array}{l}\text { NuAmp EEG } \\
\text { amplifier }\end{array}$ & Not specified & Not specified \\
\hline Yang et al. (2017) & Mind control of a robotic arm with visual fusion technology & $\begin{array}{l}\text { Neuroscan } \\
\text { amplifier }\end{array}$ & $\begin{array}{l}\text { EEG electrode } \\
\text { cap }\end{array}$ & Not specified \\
\hline Li et al. (2013) & $\begin{array}{l}\text { A Hybrid BCI system combining P300 and SSVEP and } \\
\text { its application to wheelchair control }\end{array}$ & $\begin{array}{l}\text { NuAmp EEG } \\
\text { amplifier }\end{array}$ & $\begin{array}{l}\text { EEG electrode } \\
\text { cap (LT37) }\end{array}$ & $\begin{array}{l}\text { Ag-AgCl } \\
\text { electrodes }\end{array}$ \\
\hline
\end{tabular}

*Not mentioned by the researchers. Deduced using the figures presented in the article

figures provided in the articles. The following articles, Li et al. (2013); Peng et al. (2016) indicated that the LT37 model was used. In addition, Guneysu and Akin (2013); Gui et al. (2015); Achic et al. (2016); Stawicki et al. (2016); Wang et al. (2018) used the Emotiv EPOC headset which incorporates all the components in its equipment.

Finally, regarding the sensors, 28 of 40 reviewed articles have not specified this information. Instead, Peng et al. (2016) indicated that the research used Dry spike EEG sensors while Li et al. (2013); Peng et al. (2016); Savic and Popovic (2015) indicated the usage of Ag/AgCl electrodes.

Benefits and limitations of analyzed articles: Within the reviewed literature, many advantageous features that can improve the lifestyle of human beings were found, especially for people who have MND or other types of disabilities. Health-oriented applications offer several benefits such as support to people who have difficulty performing daily tasks (e.g., feeding), help people with movement limitations (e.g., electric wheelchair) and support for physical rehabilitation.
Additionally in the field of robotics and vehicles, there are advances that are beginning to appear, since, this area can offer a great amount of benefit for society. One of the common applications are those related to humanoid robots. Multiple BCI applications have been generated in the field since, they can offer benefits such as replacing the task of human beings in dangerous situations and to perform jobs in a more efficient and faster way. On the other hand, BCI systems applied to motorized vehicles will bring great benefits since driver reactions will be perceived by the automotive system in a rapid and transparent manner, reducing the number of accidents. In addition, research on improving driving environments using brainwaves will bring significant changes to the automotive area.

Furthermore, we believe that the attempts of applying the SSVEP BCI systems in the IoT field are a good idea since the wide range of frequencies could allow the control of a large number of devices. For now, the revised solutions are not very advanced but they have great potential as they propose complete and scalable platforms. On the other hand, SSVEP is being applied in the field of 
virtual reality to simulate solutions that are difficult to implement in the real world. One of the examples is the implementation of a BCI system for controlling a real car; this solution is quite valid, since, implementing a test site for driving cars with brainwaves in the real world could be complicated, very expensive and even dangerous.

In the field of AAC, BCI systems are being used commonly for speller applications. In this aspect, although, spellers usually use P300 signals, the use of SSVEP is improving such systems, since, they deliver a higher Information Transfer Rate (ITR), more intuitive interface for users, faster response and less dependency for the user (Id and Benda).

As shown in the previous paragraphs, the BCI systems based on SSVEP provide many benefits for their users and present an interesting future. However, they also incorporate several limitations that need to be overcome.

In the case of health-oriented applications, they have the limitation that most of the works were never tested with real patients with MND or other types of disabilities. For example, rehabilitation systems such as Savic and Popovic (2015) were tested on healthy people who were supposed to need rehabilitation. This situation leads to a problem since, the systems are not be assured that they really fulfill the requirements of real users. On the other hand, navigation systems have the limitation of delivering a limited number of commands (e.g., Li et al. (2013) only allows go forward and stop while Ruhunage et al. (2017) only works at $6 \mathrm{~Hz}$ frequency). Similarly, some navigation assistance technology applications require the user to concentrate to execute specific commands and this is not possible in a real environment where there are many distractions.

On the other hand, systems for controlling vehicles also have some limitations. For example, since, the vehicles are controlled remotely, loss and delay of control signals would be a big problem. If control signals reach the vehicle with losses and delay, it could cause severe accidents. Additionally, controlling a vehicle with precision using SSVEP is very difficult; even though the user's concentration, the flickering light to which he/she is exposed would not allow him/her to do so for a long period of time.

Solutions in the IoT area are ambitious but the current prototypes are still very limited in terms of the number of commands and devices they can control. However, we believe that this is one of the areas where the applicability of the EEG-SSVEP is going to increase. Furthermore, we believe that the BCI applications oriented to virtual reality is very premature and we have to wait a little more to have more realistic applications. Finally, the spellers developed in the AAC field that use SSVEP seem to have a great future but they will have to find an adequate solution to deal with a correct distribution of stimulus frequencies since the proximity between stimuli of similar frequencies can delay responses and even make it impossible to classify.

In summary, the EEG-SSVEP based BCI systems are very interesting and demonstrate to be excellent options for a different type of applications, however, they still have several issues to be solved before being implemented in massive real-world applications.

\section{Analysis of different technological aspects of reviewed articles}

Classification algorithms: As far as the classification techniques are concerned, although, the SSVEP signals generated by visual stimuli are quite distinguishable by their frequencies (Liu et al. 2018), they require great precision. This is the reason why the study of classification algorithms is one of the main focuses of research in non-invasive BCI systems. In this aspect, the majority of systems in the reviewed articles uses popular classification algorithms such as CCA, LDA and FFT since, they achieve quite acceptable results but it is important to remember that other non-popular techniques such as Multivariate Synchronization Index (MSI) and Matched Filter Detector (MFD) look like to have better results. Finally, it is important to emphasize that more and more solutions are appearing that make use of machine learning algorithms even though they require wider knowledge to adjust its parameters and a larger amount of data/time to train and test the models.

Channels: The most used channels for gathering signals for SSVEP are O1, Oz and $\mathrm{O} 2$ because they are involved with vision. But it should be noted that many works used other channels in conjunction with those mentioned above; this is because they use a hybrid system or they are taking into account the variation that may occur signals between each test subject. In addition, as mentioned in Table 2, some jobs do not specify the channels used. This represents a limitation, since, it does not allow the studies to be replicated.

Experimentation subject: We believe that one of the aspects that most of the reviewed articles need to improve is the number of subjects of experimentation. This is because only $24.39 \%$ of the articles tested their prototypes on 10 or more subjects while $53.66 \%$ tested on 5 or fewer users. We believe that the high number of test subjects gives greater reliability of the results, demonstrates the implementation feasibility of the proposed solutions in real applications and ensures interoperability between different users.

BCI equipment: In terms of BCI equipment, only a small amount of works go into detail about the hardware (e.g., sensors and headsets) that researchers have used. 
This can be an important limitation because the possibility of replicating prototypes of previous works (e.g., for validation of results or improvement of the system) decreases considerably. Among the works that detail the used hardware stands out the usage of NeuroScan (from different models), OpenBCI and Emotiv EPOC.

Final comments: Most of the research in the BCI field has quite ambitious objectives and is being studied by different research groups worldwide. It is a field that will definitely benefit human beings, especially, those who have some physical disability. And inside of this field, the use of SSVEP signals has a great future since, it has several benefits such as high ITR, high classification accuracy and a short or null training time which translates into less dependence on the subject. In addition, the applicability of this technique in different types of systems will allow the integration of different technologies such as robotics, IoT, virtual reality and motorized vehicles.

In terms of robotics integration with BCI systems would bring significant benefits for humanity, these benefits will bring the inclusion of people with disabilities in jobs in addition to facilitating the use of robotic machinery in industries, replacing repetitive and exhausting tasks.

\section{CONCLUSION}

In this review, forty articles related to the development of EEG-SSVEP applications were analyzed. The considerable number of articles published lately shows the progress EEG-SSVEP system has had in the field of real-world BCI systems.

\section{ACKNOWLEDGEMENT}

The researchers gratefully acknowledge the financial support provided by the Escuela Politécnica Nacional for the development of the project PIS-17-15- "Control de dispositivos a través del Pensamiento (Ondas Cerebrales)”.

\section{REFERENCES}

ASHA., 2019. Augmentative and alternative communication (A A C). American Speech-Language-Hearing Association, Rockville, Maryland, USA. https://www.asha.org/public/ speech/disorders/aac/

Abhang, P.A., B.W. Gawali and S.C. Mehrotra, 2016. Introduction to Eeg-and Speech-Based Emotion Recognition. 1st Edn., Academic Press, Cambridge, Massachusetts, USA., ISBN: 9780128045312 , Pages: 198.
Achic, F., J. Montero, C. Penaloza and F. Cuellar, 2016. Hybrid BCI system to operate an electric wheelchair and a robotic arm for navigation and manipulation tasks. Proceedings of the 2016 IEEE International Workshop on Advanced Robotics and its Social Impacts (ARSO’16), July 8-10, 2016, IEEE, Shanghai, China, pp: 249-254.

Alimardani, M., S. Nishio and H. Ishiguro, 2015. BCI-teleoperated androids: A study of embodiment and its effect on motor imagery learning. Proceedings of the 2015 IEEE 19th International Conference on Intelligent Engineering Systems (INES'15), September 3-5, 2015, IEEE, Bratislava, Slovakia, pp: 347-352.

Andronicus, S., N.C. Harjanto and A. Widyotriatmo, 2015. Heuristic steady state visual evoked potential based brain computer interface system for robotic wheelchair application. Proceedings of the 2015 4th International Conference on Instrumentation, Communications, Information Technology and Biomedical Engineering (ICICI-BME'15), November 2-3, 2015, IEEE, Bandung, Indonesia, pp: 94-97.

Anindya, S.F., H.H. Rachmat and E. Sutjiredjeki, 2016. A prototype of SSVEP-based BCI for home appliances control. Proceedings of the 2016 1st International Conference on Biomedical Engineering (IBIOMED’16), October 5-6, 2016, IEEE, Yogyakarta, Indonesia, pp: 1-6.

Arksey, H. and L. O’Malley, 2005. Scoping studies: Towards a methodological framework. Int. J. Soc. Res. Methodol., 8: 19-32.

Bevilacqua, V., G. Tattoli, D. Buongiorno, C. Loconsole and D. Leonardis et al., 2014. A novel BCI-SSVEP based approach for control of walking in virtual environment using a convolutional neural network. Proceedings of the 2014 International Joint Conference on Neural Networks (IJCNN'14), July 6-11, 2014, IEEE, Beijing, China, pp: 4121-4128.

Bi, L., X.A. Fan and Y. Liu, 2013. EEG-based brain-controlled mobile robots: A survey. IEEE. Trans. Hum. Mach. Syst., 43: 161-176.

Bunce, S.C., M. Izzetoglu, K. Izzetoglu, B. Onaral and K. Pourrezaei, 2006. Functional near-infrared spectroscopy. IEEE. Eng. Med. Biol. Mag., 25: 54-62.

De Buyser, E., E. De Coninck, B. Dhoedt and P. Simoens, 2016. Exploring the potential of combining smart glasses and consumer-grade EEG/EMG headsets for controlling IoT appliances in the smart home. Proceedings of the 2nd IET International Conference on Technologies for Active and Assisted Living (TechAAL'16), October 24-25, 2016, London, UK., pp: 1-6.

Diez, P.F., V.A. Mut, E. Laciar and E.M.A. Perona, 2014. Mobile robot navigation with a self-paced brain-computer interface based on high-frequency SSVEP. Robotica, 32: 695-709. 
Farmaki, C., G. Christodoulakis and V. Sakkalis, 2016. Applicability of SSVEP-based brain-computer interfaces for robot navigation in real environments. Proceedings of the IEEE 2016 38th Annual International Conference on Engineering in Medicine and Biology Society (EMBC'16), August 16-20, 2016, IEEE, Orlando, Florida, USA., pp: 2768-2771.

Gonzalez-Mendoza, A., J.L. Perez-Benitez, J.A. Perez-Benitez and J.H. Espina-Hernandez, 2015. Brain computer interface based on SSVEP for controlling a remote control car. Proceedings of the 2015 International Conference on Electronics, Communications and Computers (CONIELECOMP’15), February 25-27, 2015, IEEE, Cholula, Mexico, pp: 93-97.

Graimann, B., B. Allison and G. Pfurtscheller, 2009. Brain-Computer Interfaces: A Gentle Introduction. In: Brain-Computer Interfaces: The Frontiers Collection, Graimann, B., G. Pfurtscheller and B. Allison (Eds.). Springer, Berlin, Germany, ISBN: 978-3-642-02090-2, pp: 1-27.

Gui, K., Y. Ren and D. Zhang, 2015. Online brain-computer interface controlling robotic exoskeleton for gait rehabilitation. Proceedings of the 2015 IEEE International Conference on Rehabilitation Robotics (ICORR'15), August 11-14, 2015, IEEE, Singapore, pp: 931-936.

Guneysu, A. and H.L. Akin, 2013. An SSVEP based BCI to control a humanoid robot by using portable EEG device. Proceedings of the 2013 35th Annual International Conference on IEEE Engineering in Medicine and Biology Society (EMBC'13), July 3-7, 2013, IEEE, Osaka, Japan, pp: 6905-6908.

Hakvoort, G., B. Reuderink and M. Obbink, 2011. Comparison of PSDA and CCA detection methods in a SSVEP-based BCI-system. Centre for Telematics and Information Technology, University of Twente, Enschede, Netherlands. https://research. utwente.nl/en/publications/comparison-of-psda-and -cca-detection-methods-in-a-ssvep-based-bci

Hamalainen, M., R. Hari, R.J. Ilmoniemi, J. Knuutila and O.V. Lounasmaa, 1993. Magnetoencephalography theory, instrumentation, and applications to noninvasive studies of the working human brain. Rev. Mod. Phys., Vol. 65, No. 2. 10.1103/ RevModPhys.65.413

He, B., S. Gao, H. Yuan and J.R. Wolpaw, 2013. Brain-Computer Interfaces. In: Neural Engineering, He, B. (Ed.). Springer, Berlin, Germany, ISBN: 978-1-4614-5227-0, pp: 87-51.

Jagadish, B., M.S. Kiran and P. Rajalakshmi, 2017. A novel system architecture for brain controlled IoT enabled environments. Proceedings of the 2017 IEEE 19th International Conference on E-Health Networking, Applications and Services (Healthcom'17), October 12-15, 2017, IEEE, Dalian, China, pp: 1-5.
Kamiya, J., 1968. Conscious control of brain waves. Psychol. Today., 1: 57-60.

Khan, M.J., A. Zafar and K.S. Hong, 2016. Hybrid EEG-NIRS based active command generation for quadcopter movement control. Proceedings of the 2016 International Automatic Control Conference (CACS'16), November 9-11, 2016, IEEE, Taichung, Taiwan, pp: 200-205.

Lee, P.L., H.C. Chang, T.Y. Hsieh, H.T. Deng and C.W. Sun, 2012. A brain-wave-actuated small robot car using ensemble empirical mode decomposition-based approach. IEEE. Trans. Syst. Man Cybern. Part A. Syst. Hum., 42: 1053-1064.

Li, W., F. Duan, S. Sheng, C. Xu, R. Liu, Z. Zhang and X. Jiang, 2017. A human-vehicle collaborative simulated driving system based on hybrid brain-computer interfaces and computer vision. IEEE. Trans. Cognit. Dev. Syst., 10: 810-822.

Li, Y., J. Pan, F. Wang and Z. Yu, 2013. A hybrid BCI system combining P300 and SSVEP and its application to wheelchair control. IEEE. Trans. Biomed. Eng., 60: 3156-3166.

Liu, C., S. Xie, X. Xie, X. Duan, W. Wang and K. Obermayer, 2018. Design of a video feedback SSVEP-BCI system for car control based on improved MUSIC method. Proceedings of the 2018 6th International Conference on Brain-Computer Interface (BCI'18), January 15-17, 2018, IEEE, GangWon, South Korea, pp: 1-4.

Meng, L., J. Jin and X. Wang, 2011. A comparison of three electrode channels selection methods applied to SSVEP BCI. Proceedings of the 2011 4th International Conference on Biomedical Engineering and Informatics (BMEI'11), October 15-17, 2011, IEEE, Shanghai, China, pp: 584-587.

Mistry, K.S., P. Pelayo, D.G. Anil and K. George, 2018. An SSVEP based brain computer interface system to control electric wheelchairs. Proceedings of the 2018 IEEE International Instrumentation and Measurement Technology Conference (I2MTC'18), May 14-17, 2018, IEEE, Houston, Texas, USA., pp: 1-6.

Nakanishi, M., Y. Wang, X. Chen, Y.T. Wang, X. Gao and T.P. Jung, 2017. Enhancing detection of SSVEPs for a high-speed brain speller using task-related component analysis. IEEE. Trans. Biomed. Eng., 65: 104-112.

Nam, C.S., A. Nijholt and F. Lotte, 2018. Brain-Computer Interfaces Handbook: Technological and Theoretical Advances. CRC Press, Boca Raton, Florida, USA., ISBN: 9781498773430.

Nicolas-Alonso, L.F. and G.G. Jaime, 2012. Brain computer interfaces: A review. Sensors, 12: 1211-1279. 
Pelayo, P., H. Murthy and K. George, 2018. Brain-computer interface controlled robotic arm to improve quality of life. Proceedings of the 2018 IEEE International Conference on Healthcare Informatics (ICHI'18), June 4-7, 2018, IEEE, New York, USA., pp: 398-399.

Peng, N., R. Zhang, H. Zeng, F. Wang, K. Li, Y. Li and X. Zhuang, 2016. Control of a nursing bed based on a hybrid brain-computer interface. Proceedings of the 2016 38th Annual International Conference of the IEEE Engineering in Medicine and Biology Society (EMBC'16), August 16-20, 2016, IEEE, Orlando, Florida, USA., pp: 1556-1559.

Perera, C.J., I. Naotunna, C. Sadaruwan, R.A.R.C. Gopura and T.D. Lalitharatne, 2016. SSVEP based BMI for a meal assistance robot. Proceedings of the 2016 IEEE International Conference on Systems, Man and Cybernetics (SMC'16), October 9-12, 2016, IEEE, Budapest, Hungary, pp: 002295-002300.

Perera, C.J., T.D. Lalitharatne and K. Kiguchi, 2017. EEG-controlled meal assistance robot with camera-based automatic mouth position tracking and mouth open detection. Proceedings of the 2017 IEEE International Conference on Robotics and Automation (ICRA'17), May 29-June 3, 2017, IEEE, Singapore, pp: 1760-1765.

Rios-Lago, M., 2008. Functional magnetic resonance and neuropsychology: basic concepts. Radiología, 50: 351-365.

Ruhunage, I., C.J. Perera, K. Nisal, J. Subodha and T.D. Lalitharatne, 2017. EMG signal controlled transhumerai prosthetic with EEG-SSVEP based approch for hand open/close. Proceedings of the 2017 IEEE International Conference on Systems, Man and Cybernetics (SMC'17), October 5-8, 2017, IEEE, Banff, Canada, pp: 3169-3174.

Savic, A.M. and M.B. Popovic, 2015. Brain computer interface prototypes for upper limb rehabilitation: A review of principles and experimental results. Proceedings of the 2015 23rd International Conference on Telecommunicat Forum Telfor (TELFOR'15), November 24-26, 2015, IEEE, Belgrade, Serbia, pp: 452-459.

Shih, J.J., D.J. Krusienski and J.R. Wolpaw, 2012. Brain-computer interfaces in medicine. Mayo Clin. Proc., 87: 268-279.

Shivappa, V.K.K., B. Luu, M. Solis and K. George, 2018. Home automation system using brain computer interface paradigm based on auditory selection attention. Proceedings of the 2018 IEEE International Conference on Instrumentation and Measurement Technology (I2MTC’18), May 14-17, 2018, IEEE, Houston, Texas, USA., pp: 1-6.

Stawicki, P., F. Gembler and I. Volosyak, 2016. Driving a semiautonomous mobile robotic car controlled by an SSVEP-based BCI. Comput. Intell. Neurosci., Vol. 2016, 10.1155/2016/4909685
Steriade, M., P. Gloor, R.R. Llinas, F.H.L. Da Silva and M.M. Mesulam, 1990. Basic mechanisms of cerebral rhythmic activities. Electroencephalography Clin. Neurophysiol., 76: 481-508.

Su, W. and Z. Li, 2017. Brain-computer interface based stochastic navigation and control of a semiautonomous mobile robot in an indoor environment. Proceedings of the 2017 2nd International Conference on Advanced Robotics and Mechatronics (ICARM'17), August 27-31, 2017, IEEE, Hefei, China, pp: 718-723.

Thakor, N.V. and D.L. Sherman, 2013. EEG Signal Processing: Theory and Applications. In: Neural Engineering, He, B. (Ed.). Springer, Berlin, Germany, ISBN: 978-1-4614-5226-3, pp: 259-303.

Turnip, A., A.I. Simbolon, M.F. Amri and M.A. Suhendra, 2015b. Utilization of EEG-SSVEP method and ANFIS classifier for controlling electronic wheelchair. Proceedings of the 2015 International Conference on Technology, Informatics, Management, Engineering \& Environment (TIME-E'15), September 7-9, 2015, IEEE, Samosir, Indonesia, pp: 143-146.

Turnip, A., D. Soetraprawata and T.A. Tamba, 2015c. Eeg-ssvep signals extraction with nonlinear adaptive filter for brain-controlled wheelchair. Proceedings of the 2015 15th International Conference on Control, Automation and Systems (ICCAS'15), October 13-16, 2015, IEEE, Busan, South Korea, pp: 1870-1873.

Turnip, A., M.A. Suhendra, K.D. Esti and P. Sihombing, 2017. Design of extraction method of SSVEP brain activity with IIR Chebyshev. Proceedings of the 2017 5th International Conference on Instrumentation, Control and Automation (ICA'17), August 9-11, 2017, IEEE, Yogyakarta, Indonesia, pp: 121-125.

Turnip, A., M.I. Rizgyawan, K.D. Esti, S. Yanyoan and E. Mulyana, 2016. Real time classification of SSVEP brain activity with adaptive feedforward neural networks. Proceedings of the 2016 3rd International Conference on Information Technology, Computer and Electrical Engineering (ICITACEE'16), October 19-20, 2016, IEEE, Semarang, Indonesia, pp: 1-5.

Turnip, M., A. Dharma, H.H. Pasaribu, M. Harahap, M.F. Amri, M.A. Suhendra and A. Turnip, 2015a. An application of online ANFIS classifier for wheelchair based brain computer interface. Proceedings of the 2015 International Conference on Automation, Cognitive Science, Optics, Micro Electro-Mechanical System and Information Technology (ICACOMIT'15), October 29-30, 2015, IEEE, Bandung, Indonesia, pp: 134-137.

Vialatte, F.B., M. Maurice, J. Dauwels and A. Cichocki, 2010. Steady-state visually evoked potentials: Focus on essential paradigms and future perspectives. Prog. Neurobiol., 90: 418-438. 
Virdi, P., P. Syal and P. Kumari, 2017. Home automation control system implementation using SSVEP based brain computer interface. Proceedings of the 2017 International Conference on Inventive Computing and Informatics (ICICI'17), November 23-24, 2017, IEEE, Coimbatore, India, pp: 1068-1073.

Walter, W.G., R. Cooper, V.J. Aldridge, W.C. McCallum and A.L. Winter, 1964. Contingent negative variation: An electric sign of sensori-motor association and expectancy in the human brain. Nat., 203: 380-384.

Wang, M., R. Li, R. Zhang, G. Li and D. Zhang, 2018. A wearable SSVEP-based BCI system for quadcopter control using head-mounted device. IEEE. Access, 6: 26789-26798.

Wang, Y., R. Wang, X. Gao, B. Hong and S. Gao, 2006. A practical VEP-based brain-computer interface. IEEE. Trans. Neural Syst. Rehabil. Eng., 14: 234-240.

Won, D.O., H.H. Zhang, C. Guan and S.W. Lee, 2014. A BCI speller based on SSVEP using high frequency stimuli design. Proceedings of the 2014 IEEE International Conference on Systems, Man and Cybernetics (SMC'14), October 5-8, 2014, IEEE, San Diego, California, USA., pp: 1068-1071.

Wu, C.M., Y.J. Chen, I.A. Zaeni and S.C. Chen, 2016. A new SSVEP based BCI application on the mobile robot in a maze game. Proceedings of the 2016 International Conference on Advanced Materials for Science and Engineering (ICAMSE’16), November 12-13, 2016, IEEE, Tainan, Taiwan, pp: 550-553.

Yang, C., H. Wu, Z. Li, W. He, N. Wang and C.Y. Su, 2017. Mind control of a robotic arm with visual fusion technology. IEEE. Trans. Ind. Inf., 14: 3822-3830.
Zhang, C., Y. Kimura, H. Higashi and T. Tanaka, 2012. A simple platform of brain-controlled mobile robot and its implementation by SSVEP. Proceedings of the 2012 International Joint Conference on Neural Networks (IJCNN'12), June 10-15, 2012, IEEE, Brisbane, Australia, pp: 1-7.

Zhang, L., X. Zhang, Z. Lu and R. Li, 2017a. A new object-oriented SSVEP-based BCI paradigm using continuous action scene. Proceedings of the 2017 IEEE 7th Annual International Conference on CYBER Technology in Automation, Control and Intelligent Systems (CYBER'17), July 31-August 4 2017, IEEE, Honolulu, Hawaii, USA., pp: 1078-1082.

Zhang, P., K. Jamison, S. Engel, B. He and S. He, 2011. Binocular rivalry requires visual attention. Neuron, 71: 362-369.

Zhang, W., F. Sun, C. Liu, W. Su, C. Tan and S. Liu, 2017b. A hybrid EEG-based BCI for robot grasp controlling. Proceedings of the 2017 IEEE International Conference on Systems, Man and Cybernetics (SMC'17), October 5-8, 2017, IEEE, Banff, Canada, pp: 3278-3283.

Zhao, J., W. Li, X. Mao, H. Hu, L. Niu and G. Chen, 2016. Behavior-based ssvep hierarchical architecture for telepresence control of humanoid robot to achieve full-body movement. IEEE. Trans. Cognit. Dev. Syst., 9: 197-209.

Zhao, R., Y. Qiao, Y. Zhu and Y. Wang, 2017. A SSVEP intelligent home service system based on CCA. Proceedings of the 2017 3rd IEEE International Conference on Control Science and Systems Engineering (ICCSSE'17), August 17-19, 2017, IEEE, Beijing, China, pp: 495-499.

Zhao, S., Z. Li, R. Cui, Y. Kang, F. Sun and R. Song, 2016. Brain-machine interfacing-based teleoperation of multiple coordinated mobile robots. IEEE. Trans. Ind. Electron., 64: 5161-5170. 